\title{
WestVirginiaUniversity
}

THE RESEARCH REPOSITORY @ WVU

Graduate Theses, Dissertations, and Problem Reports

2004

\section{Effective verbal behaviors during cognitive collaboration by older adult partners}

Kristopher J. Kimbler

West Virginia University

Follow this and additional works at: https://researchrepository.wvu.edu/etd

\section{Recommended Citation}

Kimbler, Kristopher J., "Effective verbal behaviors during cognitive collaboration by older adult partners" (2004). Graduate Theses, Dissertations, and Problem Reports. 783.

https://researchrepository.wvu.edu/etd/783

This Thesis is protected by copyright and/or related rights. It has been brought to you by the The Research Repository @ WVU with permission from the rights-holder(s). You are free to use this Thesis in any way that is permitted by the copyright and related rights legislation that applies to your use. For other uses you must obtain permission from the rights-holder(s) directly, unless additional rights are indicated by a Creative Commons license in the record and/ or on the work itself. This Thesis has been accepted for inclusion in WVU Graduate Theses, Dissertations, and Problem Reports collection by an authorized administrator of The Research Repository @ WVU. For more information, please contact researchrepository@mail.wvu.edu. 


\title{
Effective Verbal Behaviors during Cognitive Collaboration by Older Adult Partners
}

\author{
Kristopher J. Kimbler
}

Thesis submitted to the Eberly College of Arts and Sciences at West Virginia University in partial fulfillment of the requirements for the degree of

\author{
Masters of Arts \\ in \\ Life-Span Developmental Psychology
}

Jennifer Margrett, Ph.D., Chair

Barry Edelstein, Ph.D.

Julie Patrick, Ph.D.

JoNell Strough, Ph.D.

Department of Psychology

Morgantown, West Virginia

2004

Keywords: aging, collaboration, married couples, everyday problem solving 


\section{ABSTRACT \\ Effective Verbal Behaviors during Cognitive Collaboration by Older Adult Partners}

Kristopher J. Kimbler

The present study examined interactive behaviors in older adults $(N=80$ individuals). The main goal of the current study was to examine the process of collaboration and how the interactive process related to the collaborative outcome. Three research questions were addressed. First, did partners exhibit similar levels of interactive behavior or did collaborative behaviors vary by partner familiarity, performance order, or sex? Second, to what extent did individual variables predict interactive behaviors? Finally, how were the dyadic interactive behaviors related to the outcome of the collaboration? The proportion of interactive behaviors varied based on performance order and partner familiarity. In addressing the second specific aim of this study, it was found that performance order, partner familiarity, and partner characteristics were predictive of select interactive behaviors. The third aim of the current study suggests that performance order, partner familiarity, and partner's interactive behaviors were significant predictors of the collaborative outcome. 


\section{ACKNOWLEDGEMENTS}

I would first like to thank all of the members of my thesis committee: Drs. Jennifer Margrett, Barry Edelstein, Julie Patrick, and JoNell Strough. The guidance and assistance they provided throughout the entire course of the project was extremely valuable and greatly appreciated. The contributions made by my mentor, Dr. Jennifer Margrett were especially appreciated. She provided an enormous amount of advice and contributed greatly to the planning and implementation of this study. In addition, Dr. Margrett consistently gave not only professional support but also unmatchable enthusiasm and encouragement. Her great efforts truly made this project possible.

I would also like to thank my fellow graduate students for providing friendship, professional advice, and social support throughout my graduate studies. In addition, the entire faculty in the life-span development program was always encouraging, supportive, and available to provide assistance in any way possible. Family and friends have also encouraged me and provided support, especially my fiancée Leah Merritt, my brother Chad Kimbler, and my parents James and Debbie Kimbler. 


\section{TABLE OF CONTENTS}

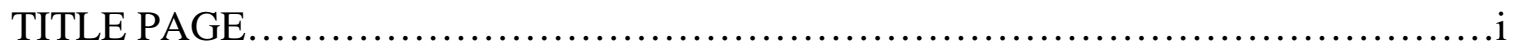

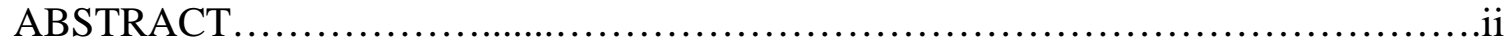

ACKNOWLEDGEMENTS.............................................................ii

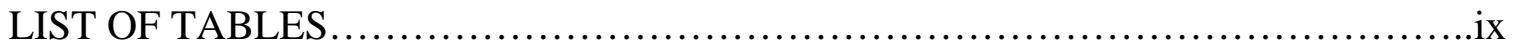

LIST OF FIGURES................................................................

LIST OF APPENDICIES........................................................

INTRODUCTION ..................................................................

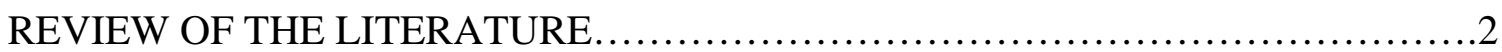

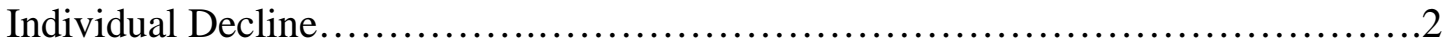

Minimizing Losses............................................................

Collaboration...........................................................4

Collaboration Throughout the Life Span $\ldots \ldots \ldots \ldots \ldots \ldots \ldots \ldots \ldots \ldots \ldots \ldots \ldots \ldots \ldots$

Infancy..........................................................

Childhood and Adolescence............................................

Adulthood and Aging..................................................

Factors Influencing Collaboration.....................................13

Situational Factors...................................................14

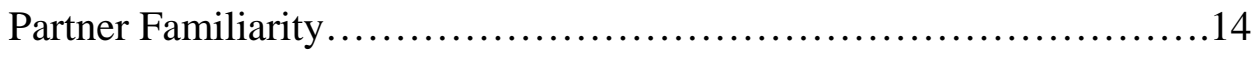

Expectations.....................................................14

Gender.......................................................15

Ability Level..................................................16

Personality...................................................16 
Quality of the Interaction........................................17

Study Rationale............................................................ 19

METHOD............................................................20

Participants..............................................................20

Measures..............................................................20

Everyday Problems Test................................................21

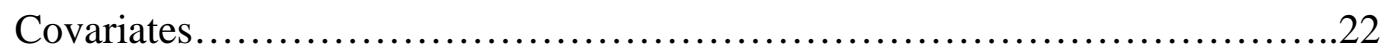

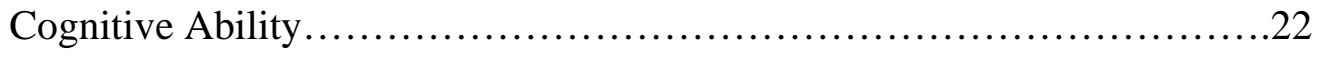

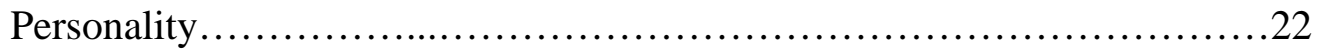

Expectations.....................................................23

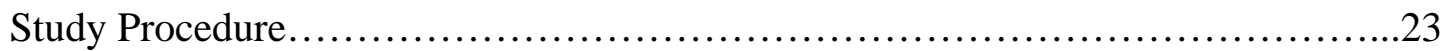

The Development of Coding Measures and Procedures...........................24

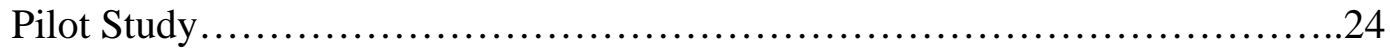

Definitions for Basic Categories of Behaviors............................24

Pilot Study Procedure.............................................24

Pilot Study Reliability............................................25

Problems Identified in the Pilot Study ................................26

Revised Coding Scheme.............................................28

Definitions for Basic Categories of Behaviors.........................28

Demands...................................................... 28

Tutoring......................................................28

Task Irrelevance...............................................29

Encouragement.................................................30 
Descriptive Codes...................................................

Revised Coding Procedure...................................................

Establishing Coding Scheme Reliability ................................32

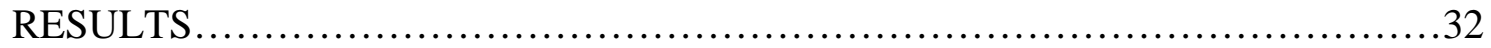

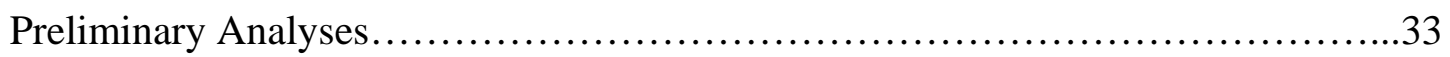

Descriptive Analyses....................................................33

Inter-relationship Between Variables....................................34

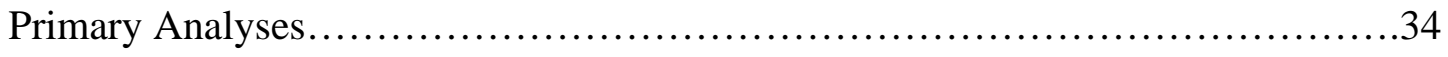

Group Differences in Interactive Behaviors....................................35

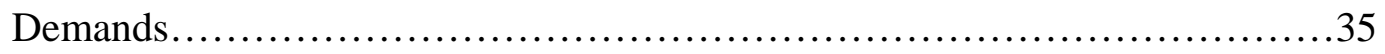

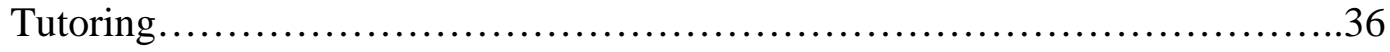

Task Irrelevance........................................................

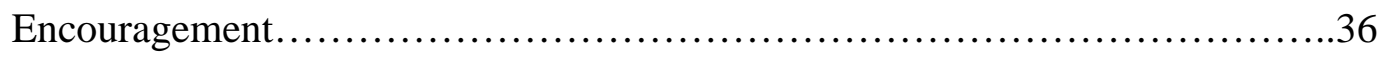

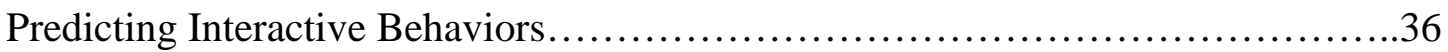

Demands............................................................... 37

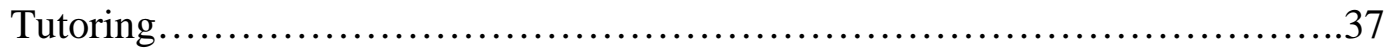

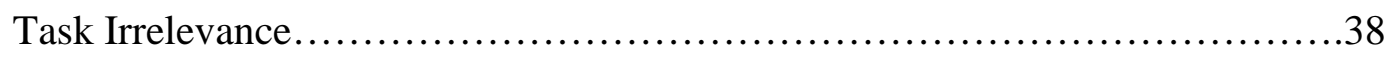

Encouragement...........................................................

Predicting the Collaborative Outcome...........................................38

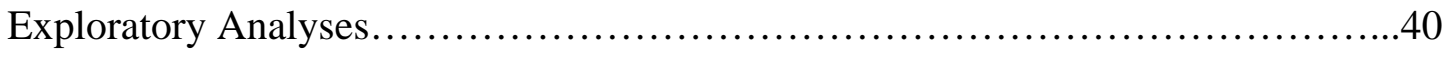

Beginning, Middle, and End Temporal Segments............................40 
Group Differences in Interactive Behaviors at Beginning, Middle, and End.

Demands.

Tutoring.

Task Irrelevance

Encouragement..................................................42

Predicting Interactive Behaviors......................................42

Demands......................................................... 42

Tutoring........................................................43

Task Irrelevance..................................................43

Encouragement.................................................43

Predicting Collaborative Outcome.........................................43

DISCUSSION........................................................44

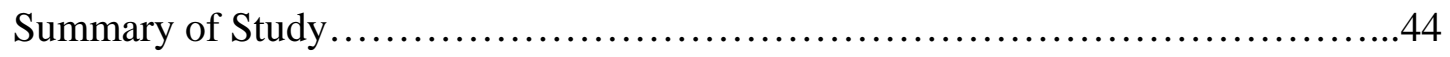

Summary of Results...................................................45

Differences in Interactive Behaviors..................................45

Predictors of Interactive Behaviors....................................46

Predictors of Collaborative Outcome....................................46

Exploratory Analyses...............................................47

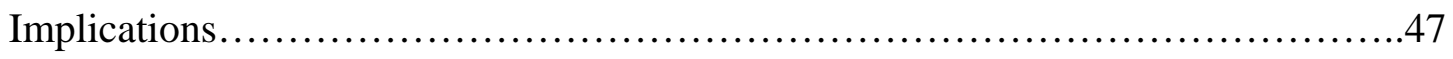

Differences in Interactive Behaviors...................................4 47

Predictors of Interactive Behaviors....................................50

Predictors of Collaborative Outcome....................................51

Limitations and Future Directions...........................................53 
Conclusions.............................................................. 55

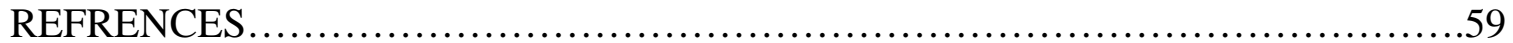




\section{LIST OF TABLES}

1. Summary of ANOVAs Comparing Subsample

Characteristics to Full Sample Characteristics.................................67

2. Descriptive Statistics for Personality Variables,

Cognitive Ability, and Collaborative Outcome

3. Total Frequencies and Proportions of Behaviors

Exhibited Throughout the Everyday Problems Test.

4. Bivariate Correlations Between Self Behaviors and

5. Analysis of Variance for Demands........................................... 71

6. Analysis of Variance for Tutoring.......................................... 72

7. Analysis of Variance for Task Irrelevance....................................73

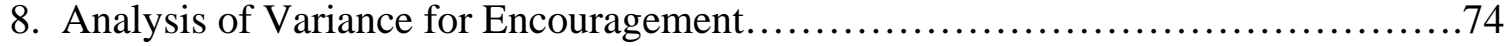

9. Summary of Hierarchical Regression Analysis

Predicting Demands..................................................... 75

10. Summary of Hierarchical Regression Analysis

Predicting Tutoring............................................................ 76

11. Summary of Hierarchical Regression Analysis

Predicting Task Irrelevance.

12. Summary of Hierarchical Regression Analysis

Predicting Encouragement.

13. Summary of Hierarchical Regression Analysis

Predicting Everyday Problem Solving Performance

Difference Score.

14. Proportion of Interactive Behaviors Overall and During

Beginning, Middle, and End Session Segments.

15. Analysis of Variance Assessing Group Differences in

Demands at Beginning, Middle, and End Session Segments.... 
16. Analysis of Variance Assessing Group Differences in Tutoring at Beginning, Middle, and End Session Segments

17. Analysis of Variance Assessing Group Differences in Task Irrelevance at Beginning, Middle, and End Session Segments

18. Analysis of Variance Assessing Group Differences in Encouragement at Beginning, Middle, and End Session Segments

19. Summary of Separate Hierarchical Regressions

Predicting Demands During the Beginning, Middle, and End Session Segments.

20. Summary of Separate Hierarchical Regressions

Predicting Tutoring During the Beginning, Middle, and End Session Segments.

21. Summary of Separate Hierarchical Regressions

Predicting Task Irrelevance During the Beginning, Middle, and End Session Segments.

22. Summary of Separate Hierarchical Regressions

Predicting Encouragement During the Beginning, Middle, and End Session Segments.

23. Summary of Hierarchical Regression Analysis Predicting Everyday Problem-solving Performance

Difference Score by Session Segments.

24. Summary of Results .90

25. Summary of Intraclass Correlations Between Partners’ Interactive Behavior. 


\section{LIST OF FIGURES}

1. Relation of Session Segment \& Tutoring Behaviors..............................93

2. Interaction Between Partner Familiarity and Session Segment for Task Irrelevance..............................................................94 


\section{LIST OF APPENDICIES}

APPENDIX A: Everyday Problems Test Example Stimulus..........................95

APPENDIX B: WED Transcript Guidelines....................................96

APPENDIX C: WED Transcript Coding Manual .................................98

APPENDIX D: WED Unitization Rules..........................................111

APPENDIX E: Rules for Calculating Unitization Reliability ......................113 


\section{INTRODUCTION}

Research has consistently found that individuals experience losses in fluid abilities as they grow older (e.g., Salthouse, 1991; Schaie, 1996). In addition, it has also been found that there are losses in processing speed associated with old age (Salthouse, 1993). As a result of these declines, losses of individual functional ability may occur among older adults. Functional ability, however, may be compensated for in many ways. One strategy that is thought to reduce individual losses in functional performance among older adults is the use of social partners through collaboration (Dixon \& Bäckman, 1995). For example, Dixon and Gould (1998) found that older married couples received more of a benefit from collaboration than older unfamiliar couples, younger unfamiliar couples, and younger married couples. Margrett and Marsiske (2002) found in the present data set that collaboration was indeed beneficial to problem solving performance and that married dyads performed better than stranger dyads. Staudinger and Baltes (1996) also found that collaboration was beneficial to older adults in a study conducted examining collaboration on wisdom related tasks. This study found that cognitive functioning could be increased by both external (person to person) and internal (one person considering what a friend or relative would do in that situation) social interactions.

The present study adds to the literature by examining the process that affects the outcome or product of the collaborative experience. In this study, the aspect of the process under examination included interactive behaviors displayed during the collaborative session. The collaborative outcome consisted of a difference score on the Everyday Problems Test (EPT; Willis \& Marsiske, 1993), which was determined by subtracting each participant's individual score from their score when they worked with a 
partner. This type of research is needed because it links the process of collaboration to the product of collaboration. More specifically, the current study examined how individual variables (e. g., cognitive ability, collaborative expectations, and personality) in relation to the interactive dimensions (i.e., demands, tutoring, task irrelevance, and encouragement) affect the quality of the collaboration. This line of study is important as it may help define what aspects of the dyadic social interaction are associated with effective outcomes of collaboration among older adults.

\section{REVIEW OF THE LITTERATURE}

\section{Individual Decline}

In recent history, industrialized societies have displayed a continuing ability to promote longevity among its citizens. As a result, the population of older adults in industrialized societies is growing at an increasingly rapid rate. In the United States, life expectancy has increased from 47 years in 1900 to 75.5 years in 1991 and is continuing to rise (U.S. Census, 2001). Consequently, there has been an increased need to identify cognitive changes that take place during old age as well as effective ways to overcome problems that may be associated with old age.

The aging literature has demonstrated that there are many changes that occur in later life. Much of this literature focuses on cognitive changes. It was once widely believed that intelligence decreases with age after middle adulthood, however, research suggests that looking at intelligence as a single factor may provide an oversimplified view of the changes that actually occur (McArdle, Hamagami, Merideth, \& Bradway, 2000). It has been proposed that a more realistic understanding of cognitive change can be obtained by distinguishing intelligence as two separate types (crystallized and fluid; 
Horn \& Cattell, 1967). Studies have shown that fluid intelligence (the type of intelligence that deals with reasoning ability in novel situations) peaks sometime during early adulthood and declines in old age (Schaie, 1996). Crystallized intelligence on the other hand, deals with knowledge learned through life experiences, and increases through middle adulthood and does not decrease as early or as rapidly as fluid intelligence (Schaie, 1996). There has also been support showing that the decline of fluid intelligence starts at midlife, is continuous throughout adulthood, and is not limited to people with poor health or low levels of education (Salthouse, 1991). In addition to decreased fluid intelligence, it has also been found that there are losses in sensory processing speed associated with old age (Salthouse, 1993).

\section{Minimizing Losses}

Given the focus in the literature concerning age-related declines in fluid intelligence combined with negative stereotypes associated with older adults, many people believe that it is normal for older adults to experience great loss in their functional abilities in their day-to-day lives. This conclusion, however, is not correct. There is a substantial amount of literature that deals with successful aging, showing that individuals are able to function at high levels during their daily activities in spite of the declines that occur during old age (e.g., Baltes \& Baltes, 1998; Collins, 2001; Vaillant, \& Makamal, 2001; Westerhof, Dittman-Kohli, \& Thissen, 2001).

One of the most influential theories describing how individuals are able to accomplish maximized benefits and minimized losses is the theory of selection, optimization and compensation (SOC; Baltes \& Baltes, 1998). This theory states that individuals select activities that emphasize their strengths and then focus on these 
activities in order to maintain or optimize their performance. The individuals may compensate by adopting additional strategies in an attempt to maintain high ability levels in these domains (Baltes, 1997). One example of this type of compensation would be the utilization of social relationships through collaboration to assist in the performance of cognitive tasks (Dixon \& Bäckman, 1995).

\section{Collaboration}

\section{Collaboration Throughout the Life Span}

Although investigations of how older adults can benefit from collaboration are a relatively new trend, there is a great deal of theory and research dealing with collaboration that has been generated from a focus on school-aged children. A theory by Lev Vygotsky proposes that social interaction is the key element to cognitive development. Through interactions with others, children are able to learn and increase their cognitive abilities. Such interactions result in children developing at their optimal level, known as the zone of proximal development (Vygotsky, 1994/1934). It is therefore believed that parents (or other adults / experts) can enhance a child’s cognitive development through scaffolding behaviors. Scaffolding includes presenting the child with a task that they are unable to complete independently but are able to solve with assistance. The child's ability level is then increased as he or she develops an understanding of the task through participating in the collaborative interaction. As ability in a certain domain increases, the amount of assistance provided by the parent or more skilled individual decreases. It is hypothesized by Vygotsky that such interactions lead to the child reaching his or her peak level of cognitive development or zone of proximal development (Brown, 1999; Hogan \& Tudge, 1999; Wertsch, 1999). One important 
aspect of Vygotsky's theory that leads to its utility in studying cognitive development at periods across the life span is the idea that child cognition is not only aided by an adult. In fact, this theory suggests that a peer that is more experienced in a given domain can also enhance one’s cognitive abilities (Tudge, \& Rogoff, 1999). Based on this theoretical background, one would predict that tutoring and demands would benefit collaboration as long as the more expert individual was the one controlling the task and giving advice. In a recent review, De Lisi and Goldbeck (1999) describe how Piaget also believed that collaboration could be an important aspect of cognitive development. According to Piaget's theory, children are able to construct mental images of reality from exploring their environment in a scientific way. Piaget also examined the role of socialization on cognitive development. Piaget's theory emphasized the need for collaboration between peers opposed to children collaborating with an adult or expert. When collaboration involves individuals with varying expertise in a given domain, the less knowledgeable individual may accept the ideas proposed by the expert without truly understanding the concepts. When equal ability peers collaborate, however, each individual would be more likely to critically evaluate ideas that are presented resulting in a better understanding and a more qualitative gain in cognition (De Lisi \& Goldbeck, 1999).

The seminal theories developed by Piaget and Vygotsky lead to a great deal of interest in the link between social interaction and cognition. Although much of this research has focused on examining social cognition as part of cognitive development during childhood, research on collaboration has extended to the study of how working with a partner is related to cognitive performance in all age groups. It is not sufficient, 
however, to simply determine what an individual gains (or loses) from collaboration. To truly understand how interacting with others relates to cognition, it is essential to learn how such interactions lead to changes in performance. A great deal of research has been devoted to collaboration in an attempt to understand the product (gains/loses) as well as the process that leads to the collaborative outcome (i.e., Dixon \& Gould, 1998; Margrett, 1998; Berg, Johnson, Meegan, \& Strough, 2003). Typically, observational studies focus on studying the process of any phenomenon while more traditional quantitative experimental designs can reveal a great deal about the product (Reinharz, 1994).

Research on collaboration has examined both the process and product throughout the life span.

\section{Infancy}

Research examining parent-infant collaboration is somewhat rare. Research that has been conducted in this area, however, suggests that the most important factor in determining the performance or product of parent-infant dyadic collaboration appears to be the interaction style of the parent. Typically, research studying collaboration between infants and parents focuses on either the process or the link between the process and the product. Infant collaborative studies rarely only examine the product of collaboration because it can be assumed that infants will almost always benefit from a parents’ assistance as it may be difficult for infants to understand the nature of tasks individually. Some studies therefore chose to focus only on the process. For example, in a study conducted by Heckhausen (1999) the process of collaboration was examined as researchers coded for scaffolding behaviors during a shape sorting task. Mother-infant interactions were observed at five different points in time as the mother assisted the infant 
in learning simple tasks. Mothers exhibited scaffolding behaviors and withdrew assistance as the infants became increasingly skilled at the task (Heckhausen, 1999).

Research on collaboration between infants and parents also attempts to identify how aspects of the process may result in different collaborative products. A study conducted by Fagot and Gauvain (1997) linked the process with the product, examining interactions between mothers and infants at two different time points to determine if the mother's interactive behaviors during a collaborative balancing act were related to the infants' ability to perform simple tasks. The researchers also conducted a follow-up session when the infant was 5-years-old to determine if previous observations were predictive of later cognitive ability. Behaviors exhibited by mothers that were supportive, assistive, and less disapproving were related to greater task performance by the infants although long-term effects were unclear. Studies of 3-year-old toddlers also relate the process of collaboration to the product as the interactive behaviors of the parent (specifically the presence or absence of scaffolding behaviors) are important in predicting the toddlers' level of performance on assembly or building tasks (e.g., McNaughton \& Leyland, 1999; Meins, 1999; Pratt, Kerig, Cowan, \& Cowan, 1999).

\section{Childhood and Adolescence}

Collaboration research examining childhood and adolescence suggests that children benefit from collaborating with a peer or an adult as studies focus on the product of collaboration, the process of collaboration, or a combination of the product and the process. For example, when examining the product of collaboration, it has been found that friends benefit from collaboration more than acquaintances in scientific reasoning tasks (Azmitia \& Montgomery, 1993). Gender has also been found to be an important 
predictor of the collaborative product as the salience of problems while completing a group Spanish project differs for male and female adolescent groups (Strough, Berg, \& Meegan, 2001). Another study examined 9-year-olds collaborating with a peer and with an adult on an errand-planning task and found that the children collaborating with an adult perform better than the children who collaborated with peers. Those who collaborated with an adult also performed better during an individual posttest, indicating that the cognitive enhancement experienced when working with an adult generalized to later individual performances (Radziszewska \& Rogoff, 1988).

Although most of the research on childhood collaboration reports a positive product or benefits from collaboration, it is important to note that collaboration does not always affect performance similarly. One study examining the effects of collaboration on a Piagetian spatial task where adolescents were supposed to predict what would happen to the level of water in a jar that was being rotated various degrees. This study found that collaboration did not result in improved performance compared to individuals working alone (Golbeck \& Sinagra, 2000). In addition, Samaha and De Lisi (2000) found that collaboration is not always beneficial and that it can sometimes decrease performance when compared to individual performance. This study examined seventh-grade students who worked individually and with a same or other-sex partner on the Test of Nonverbal Intelligence. The participants first performed the test individually, then with a partner, and then again individually. In most cases, individual performance was higher after working with a partner. One exception, however, was when the partners were both female, the second individual performance (which occurred after working with a partner) was lower compared to the first individual performance. 
The studies examining the product of collaboration identify many variables that appear to be related to the collaborative outcome. This research provides a great deal of information about such aspects of the context, yet one can only speculate about the mechanisms behind the collaborative outcome unless details of the process are directly examined. Some research on childhood collaboration has focused on the process of collaboration. For example, it has been found that children in friend dyads perceive that they attempt to resolve conflict, are more involved, and are more cooperative than acquaintances when performing a creative writing task (Strough, Swenson, \& Cheng, 2001). These behaviors are likely to promote more effective collaboration. Research examining another topic that may be related to the collaborative process (goals in everyday problems) found that compared to other age groups, children are more concerned with competence and more likely to focus on task improvement goals as opposed to other possible goals and concerns such as interpersonal and affect goals (Berg, Strough, Calderone, Sansone, \& Weir, 1998).

Other studies examining collaboration during adolescence attempt to link aspects of the process to the product. For example, Samaha and De Lisi (2000) stated that exploratory talk, in which members of a dyad critically and constructively discuss each other's ideas, improves the level of reasoning and task performance compared to working alone when performing a nonverbal reasoning task.

\section{Adulthood and Aging}

A majority of the research examining collaboration in adulthood focuses on the product or potential benefits that older adults can experience through collaborating on cognitive tasks (i.e., Margrett, 1999; Staudinger and Baltes 1996). Some studies also 
examine younger adults to determine whether collaborative gains differ for younger and older adults (i.e., Dixon \& Gould, 1998). One way that older adults can benefit from social interactions is to collaborate with close friends or family members in order to maintain high levels of functioning when confronted with everyday problems. Theoretically, these social relationships can help to minimize and compensate for declines associated with old age (Dixon \& Bäckman, 1995). For example, if both the husband and wife focus on activities that maximize their strengths and minimize their weaknesses, it is possible that they could each be focusing on different activities and therefore be interdependent on activities that are necessary on a daily basis. It has also been speculated that this increased amount of cooperation and interdependence is very important in maintaining a marital relationship that is satisfying and beneficial to both spouses (Tuites \& Tuites, 1986). Since cooperation and interdependence appear to be important to a successful marriage, it is not surprising that older married couples often benefit more from their collaborative relationship than younger married couples (Dixon \& Gould, 1998).

Recently there have been an increased number of studies examining what type of effect collaboration has on adults. Dixon and Gould (1998) performed two experiments comparing older dyads to younger dyads. In both experiments they examined recall in retelling everyday stories. In their first experiment the researchers compared younger individuals ( $M=24$-years-old) to older individuals ( $M=68$-years-old) and found that the older individuals scored lower on recall than younger individuals. They then compared younger and older unfamiliar dyads and tetrads and found that both younger and older groups increased the same amount when compared to individuals' performance of their 
same age. Younger unfamiliar dyads and tetrads, however, still performed better on recall than older unfamiliar dyads and tetrads. In the second experiment Dixon and Gould (1998) compared the recall performance of older married couples to younger married couples. Findings demonstrate that the older married couples' recall scores were the same as the younger couples' recall scores. In addition, both the younger married couples and the older married couples had higher recall scores than the older and younger unfamiliar dyads in their first experiment. Collaboration is related to an improved product, and results suggest that collaboration may be more beneficial for older married couples compared to older unfamiliar couples, younger unfamiliar couples, and younger married couples. Dixon and Gould (1998) state that it is possible that older married couples receive more benefit from collaboration because they have a large amount of experience working as a collaborative unit and may be "collaborative experts." This supports the idea that because older adults, especially older married couples, perform many daily activities collaboratively. They are able to work together and compensate for cognitive decline.

Another example of cognitive collaboration benefiting performance in later life is a study conducted by Staudinger and Baltes (1996) examining wisdom. This study found that cognitive functioning could be enhanced by social interactions. This concept, known as “interactive minds” is unique because it deals with both external (person to person) and internal (one person considering what a friend or relative would do in that situation) interactions on wisdom related tasks. It was also found in this study that older adults scored the highest on this type of wisdom and that interactive situations were strongly associated with superior performance (Staudinger \& Baltes, 1996). These studies 
demonstrate how significant others working together on daily activities, appears to be a very important aspect of successful aging. Therefore, it is important to understand the specific benefits of collaboration among older adults and their significant others as well as the mechanisms underlying the collaborative process.

Using the data under examination in the present study, Margrett (1999) examined the problem-solving performance of ninety-eight familiar (married couples) and unfamiliar (other-sex strangers) dyads and compared individual and collaborative performance on instrumental, social, and errand planning tasks. The results showed that collaboration was indeed beneficial to problem solving performance. Consistent with the findings of Dixon and Gould, collaboration was more beneficial to married couple dyads than to stranger dyads on the Everyday Problems Test (EPT). On two other tasks (the Errand Planning Task and The Everyday Problem-solving Inventory), collaboration with a spouse did not lead to a greater improvement compared to collaboration with a stranger. In these two tasks, however, collaboration was beneficial (Margrett, 1999).

Not all studies examining the product of collaboration between adult collaborators have found that collaborative performance is significantly greater than individual performance. In fact, some research has found that collaboration can result in poorer performance than individual performance. For example, in some recall memory tasks, research suggests that collaboration actually hinders performance. Collaborating with a friend, however, served as somewhat of a buffer as these individuals performed at higher levels than stranger dyads (Anderson \& Roenberg, 1996).

In addition to investigating the collaborative products, research on collaboration among adults has also examined the collaborative process. One area of research that is 
likely related to the collaborative process, deals with the salience of different goals when faced with everyday problems. In adulthood there is a shift from primarily having taskrelated goals to focusing more on interpersonal goals (Berg, Strough, Calderone, Sansone, \& Weir, 1998). For an example of interpersonal goals, a study examining collaboration on errand and vacation planning, young and old adult couples stated that working together on tasks could strengthen their relationship (Berg, Johnson, Meegan, \& Strough, 2003). Another study that focused on the collaborative process was conducted by Gould, Kurzman, \& Dixon (1994). This study examined the verbal behaviors of younger and older adult dyads that were either married or unacquainted during a recall task. Individuals demonstrated more task discussion and sociability during the end of the collaborative task. The beginning of the task consisted of more independent statements about the stimulus.

Other research has attempted to link the collaborative process with the product. A study conducted by Hollingshead (1998) found that intimate couples have also been found to benefit more from working face-to-face on tasks testing memory and retrieval. These intimate individuals could outperform unfamiliar couples as well as intimate couples communicating over computer networks presumably due to the increased familiarity as well as the availability and importance of nonverbal communication. Eye contact was hypothesized to be particularly important (Hollingshead, 1998).

\section{Factors Influencing Collaboration}

As this brief review of the literature demonstrated, the collaborative product or outcome in older adults is typically positive but can also lead to no differences or declines in performance. With regard to older adults, collaboration appears to be a 
potentially important aspect in minimizing the effects of individual decline that are associated with old age. Collaboration, however, may be differentially effective. Thus, it is important to examine what factors determine whether the collaborative experience will produce results that are higher, the same, or lower than individual performance. Strough and Margrett (2002) state that the outcome of collaboration is likely dependent on a combination of individual characteristics, relationship characteristics, and task characteristics. Potentially influential factors addressed in the current study include partner familiarity, gender, individual ability, collaborative expectations, and interaction quality. Several factors addressed in the current study are described below.

\section{Situational Factors}

Partner Familiarity. The degree of familiarity between collaborating partners appears to influence the outcome of dyad collaboration. Dixon and Gould (1998) found that on a story recall task, older married couples received more of a benefit from collaboration than younger married couples, which possess less collaborative history. Margrett (1999) supports this idea and found in the data currently under examination that married older dyads performed better than stranger dyads on the EPT.

Expectations. One aspect that has been found to be related to the interaction and outcome of collaboration is expectations that individuals have about the situation or individuals with whom they will be collaborating. Harris (1990) examined the effect of giving participants fictitious information about one of their partner's ability would affect the interaction of collaboration when performing decision-making tasks. Harris found that when the participants were given negative information about their partner's ability, they rated their partner more negatively after the collaborative experience and allowed 
their partner to have less influence in decision making. In addition, the participants who were the target of these negative expectations rated themselves as being less intelligent after the collaboration. Another study looking at expectations toward individuals in a collaborative setting found that negative performance expectations held toward a certain individual, lead to the individual who is viewed negatively to talk less and to have less influence over other group members. Positive expectations led to more influence and an increase in opportunities to perform or state opinions (Driskell \& Mullen, 1990).

Gender. In addition to expectations, the gender of the individuals in the dyad also appears to be important when assessing collaboration. One study found an interaction between gender and partner familiarity when studying self-presentational motives (wanting to be perceived as friendly, competent, and ethical) in dyads (Leary, Nezlek, Downs, Radford-Davenport, Martin, \& McMullen, 1994). The results showed fewer selfpresentational motives when interacting with a familiar partner that is of the same sex compared to increased self-presentational motives when interacting with an unfamiliar same sex partner, an unfamiliar other-sex partner, and a familiar other-sex partner (Leary, et al., 1994). Another study found that disagreeing values and beliefs could lead to confrontation, which can also affect the quality of a collaborative interaction. Nonconfrontational interactions were found to be more effective in collaboration than confrontational interactions and women were better at detecting disagreements in a value based communication task (Wallace, Martin, McMillan, \& Mell, 1999). Margrett and Marsiske (2002) found, in the data being further analyzed in the present study, gender differences in adults' collaboration in familiar and unfamiliar other-sex dyads performing everyday tasks. Specifically, men were more influential especially when the task was 
ambiguous. Women reported being less satisfied with collaborative teamwork when working with an unfamiliar partner. Taken together these studies suggest that gender could be related to how individuals perform in a collaborative setting as well as how they interpret and how much influence they have on the collaborative process.

Ability Level. The similarity of the individuals’ ability level is an aspect of collaboration that also appears to affect the performance outcome. Fuchs, Fuchs, Hamlett, and Karnes (1998) examined how different ability levels affect collaborative outcomes among elementary school students. They found that two high achieving individuals perform best in collaboration compared to two low achieving individuals or one high achieving individual and one low achieving individual. The students were divided into pairs and collaborated on mathematical tasks. The results showed that collaboration was most beneficial for pairs when both individuals were high in mathematical ability, followed by pairs with one person high in ability and one person low in ability. The pairs with two individuals with low mathematical ability still benefited from collaboration although not as much as the other two types of pairs. Thus, the ability of each individual in a collaborative setting appears to impact the performance of the dyad as a whole.

Personality. An additional factor that impacts the quality and effectiveness of a collaborative environment is the personality characteristics of the individuals involved in the interaction. Dill and Anderson (1997) found that people with aggressive personalities had more hostile expectations when asked to predict the outcome of dyadic interactions. Brandstatter and Farthofer (1997) also demonstrated that personality might be important in a collaborative setting. Their study found that in groups focused on finding task 
solutions, men who were high on emotional stability were able to have a greater influence on the rest of the group. On the other hand, women were most influential when they were low in emotional stability and independence. It therefore appears that personality characteristics may influence the interactions that occur in a collaborative setting.

There is a great deal of support for examining the big five factors of personality, which include neuroticism, extraversion, openness, agreeableness, and conscientiousness (Costa \& McCrae, 1995). Theoretically, extroversion and openness could be very important aspects of collaboration. Individuals low in openness, for example, may be especially resistant in collaborating with an unfamiliar partner in an unfamiliar situation. Extroversion should also be an important factor that may predict how involved someone becomes in the collaborative process. A highly introverted individual, for example, may not share much information with his or her partner, especially if his or her partner is a stranger.

Quality of the interaction. The quality of the interaction between collaborating individuals has also been linked to the outcome of collaboration. Samaha and De Lisi (2000) state that both the quality of interaction and active exchange of ideas are important in determining the outcome of a collaborative task.

Many of the important factors such as gender, partner familiarity, values and beliefs of the individuals, and the ability of the individuals can be measured prior to the collaborative experience. The quality of the interaction and the level of idea exchange, however, cannot be measured until after the collaboration. The most common method for assessing the quality of an interaction is through qualitative coding and rating of specific interactive behaviors. Golbeck and Sinagra (2000) argue that examining adults’ 
discussions during a collaborative problem-solving interaction is an effective way to determine what affects the development of new knowledge for the dyad.

Tuites and Tuites (1986) suggested that in married couples, some of the most important interactive qualities of maintaining high levels of cooperation and interdependence may include openness, encouragement, and problem-solving behaviors. Azmitia (1988) studied interactive behavior variables in younger samples. She examined problem solving ability while performing a building task among children paired in dyads and found that the frequency of task-related statements were related to collaboration outcomes. Specifically, those dyads that displayed high levels of task-related behaviors benefited the most from a collaborative experience. Williams (2001) found that another interactive behavior, tutoring, was important when dyads were faced with a task to complete. In this study, children were questioned about how they interacted when working with peers. In most cases, children would report that one individual would take the "teacher" role while the other child would take the "student" role.

As demonstrated by many of these studies, verbal behaviors seem to have a large effect on the quality of the interaction as well as the impact that collaboration can have. Many studies looking at different forms of social interactions have supported this claim. In a study by Burgio, Burgio, Engel, and Tice (1986), it was found that verbal behaviors alone were predictive of increased task performance. A multiple baseline design was used to show that verbal praise given by staff members significantly increased the walking ability of residents in a nursing home setting. This effect was found to last over one month after the study was completed. 
Sagie (1996) examined group interactions in problem solving situations. It was found that the type of verbal communication used by the group leader had an impact on group performance as well as attitudes that group members had. It was found that when leaders were very active in directing group activity exclusively toward completing the task at hand, the group members performed at higher levels than group members with other types of leaders. The members of groups whose leaders were more focused on encouraging participation had the best attitudes. The leaders that were the most effective overall, however, demonstrated verbal behaviors that were a combination of directing the group toward their goals and encouraging equal participation.

\section{Study Rationale}

The present study used preexisting data to examine how a variety of factors related to the interaction involved in collaborative problem solving of everyday problems among older dyads. Three primary research questions were addressed. First, did partners exhibit similar levels of interactive behaviors during collaboration or did collaborative behaviors vary by partner familiarity or gender? This aim examined the extent to which the participants displayed behaviors including demands, tutoring, task irrelevance, and encouragement. Second, to what extent did individual variables predict the interactive behavior variables? This question considered the impact of similarities and differences between the partners in ability, expectations, gender, and personality. It was determined whether or not these characteristics were predictive of the interactive behaviors. Finally, how were the dyadic interactive behavior variables related to the outcome of the collaboration? This aim attempted to determine how the process of the collaborative 
performance (interactive behaviors) related to the product of collaboration on the EPT (an improvement or decline in score as a result of collaboration).

\section{METHOD}

\section{Participants}

The sample was recruited from the Detroit and Ann Arbor metropolitan area using various recruiting techniques and each individual received twenty dollars for participating. The minimum age to qualify for the study was fifty-five-years-old and the mean age for the couple had to be at least sixty years. The couples had to be living together legally married for at least fifteen years. The individuals were also free from impairment in three Activities of Daily Living (i.e., bathing, dressing, and personal hygiene). The participants in this study consisted of 40 older adult married couples ( $N=$ 80 individuals), a random subsample of a larger study on collaboration (Margrett, 1999). To assure that the subsample was similar to the original sample, analysis of variance (ANOVA) tests were conducted comparing the subsample to the total sample on age, education, income, and marriage length. No significant differences were found (See Table 1). The average age of participants was 71.7 years (range $=59-88$; $\underline{\mathrm{SD}}=5.27$ ). The mean education level and yearly income were 15.44 years (range $=9-22 ; \underline{\mathrm{SD}}=$ 2.84 ) and $\$ 40,419$ ranging from $\$ 20,000$ to over $\$ 50,000$ ( $\underline{\mathrm{SD}}=11,430$ ) respectively. Seventy nine percent of the participants were Caucasian, 20\% African American, and 1\% reported a multi ethnic background.

\section{Measures}

Several measures were administered during the procedures of the original study on collaboration. The constructs that were assessed in this study included everyday 
problem solving, cognitive ability, collaborative expectations, and personality (See Table 2 for the mean, standard deviation, and range for all independent and dependant variables except for interactive behaviors, which are presented in Table 3). The coding measures and procedures, however, were developed after the original study had been completed as a method of examining the transcripts of the interactive behaviors displayed in the collaborative setting. As demonstrated by the means for problem solving, cognitive ability, collaborative expectations, and personality, ceiling and floor effects were not problematic.

\section{Everyday Problems Test}

The Everyday Problems Test (EPT; Willis \& Marsiske, 1993) was designed to test older adults’ ability to solve problems that are related to health, cooking, finances, shopping, housekeeping, transportation, and telephone use (Willis \& Marsiske, 1993). In this task, participants solved age-relevant problems such as constructing a medication schedule. Seven stimuli are presented to participants related to everyday problems (See Appendix A for an example EPT stimulus). Participants are then asked to answer two questions related to the stimulus. The number of items answered correctly out of the fourteen-item test measured performance. Participants completed two parallel forms of the EPT that had previously been found to be of equal difficulty (Willis \& Marsiske, 1993). One form was completed alone and the other was completed with a partner. The collaborative outcome was determined by the difference between an individual's alone and collaborative score on the EPT (See Table 2 for variable descriptive statistics). 


\section{Covariates}

\section{Cognitive Ability}

Cognitive ability (g) was assessed by forming a composite from three tests that examine basic cognitive ability including verbal ability, inductive reasoning, and processing speed. Verbal ability was obtained with the Verbal Meaning Test (Thurstone, 1962) where participants were scored based on their ability to identify the correct definition of various words. The Number Comparison Test was used to determine perceptual speed (Ekstrom, French, Harman, \& Darman, 1976). In this test, participants were asked to compare sets of numbers and to indicate whether the numbers were the same or not. Inductive reasoning was measured with the Letter Series Test (Thurstone, 1962). In the letter series test, participants were instructed to examine the relationship between letters and choose what letter would come next in the series. A composite score was used instead of each individual cognitive score to be parsimonious and to reflect more general cognitive ability across different domains.

\section{Personality}

The short form of the NEO-PI measured personality along five traits: Neuroticism, Extraversion, Openness, Agreeableness, and Conscientiousness (Costa \& McCrae, 1992). To be more parsimonious, initial correlations were calculated to determine the relationship between neuroticism, extroversion, openness, agreeableness, and conscientiousness with the collaborative outcome. Although none of the personality characteristics were significantly correlated with the collaborative outcome, openness and extroversion were more correlated with the product of collaboration $(r=.18$ and -.10 
respectively) than the other personality factors. Openness and extroversion were therefore the only two aspects of personality included in further analyses.

\section{Expectations}

Individuals' expectations about their collaborative performance were also assessed. Each participant was asked to predict how well he or she would perform on the EPT with their partner. The measure consisted of a five item questionnaire using a five point Likert Scale. The questions assessed expected performance satisfaction, whether participants expected a great deal of collaboration or competition to occur, and if they thought they would likely work with their partner again. Individuals who worked with an unfamiliar partner were exposed to their partner while completing demographic information, initial tests, and during a break so they could become acquainted and have some interaction before completing the expectations questionnaire.

\section{Study Procedure}

In the study from which the data being examined was taken, couples were matched on ethnicity, age, and socioeconomic status, and were randomly assigned to work with their spouse or an other-sex stranger from another couple. The testing session was three hours long and began with two couples together in a room. Participants then completed demographics and measures of individual characteristics. Participants were then split into dyads consisting of either their spouse (familiar) or the other-sex spouse from another married couple (unfamiliar) and were taken to separate rooms. The dyads were told to work together on the problem solving tasks, to discuss the problem, and to each write down their own answer to each item. By allowing each individual to choose his or her own answer, the dyad would not necessarily have to reach an agreement, 
allowing each individual to take what he or she wanted from the collaborative experience. In addition, there was another phase where the dyad members worked alone to solve the problem solving tasks and was told not to collaborate in any way with their partner, measuring individual ability. Counterbalancing was used so that half of the dyads collaborated first and half worked alone first. The parallel forms of the EPT were also counterbalanced.

The Development of Coding Measures and Procedures

\section{Pilot Study}

\section{Definitions for Basic Categories of Behaviors}

Four coding categories that were used in the pilot study were also used in the revised coding scheme although several changes were made based on the results of the pilot study. Dominance was considered to be any verbal behaviors that were intended to control one's partner. This included controlling the session with excessive verbosity. Tutoring included giving advice on strategies to complete the task. Practical assistance was not considered tutoring. Task irrelevance was coded as and verbal behaviors not directly related to completing the task. Encouragement included verbal behaviors intended to support one's partner. Two other categories (problem solving and collaborative responsiveness) were also included in the pilot study but were not included in the revised coding scheme due to a lack of reliability.

\section{Pilot Study Procedure}

A coding scheme was developed to better understand the process of collaboration. The interactive behaviors that were coded were chosen based on previous research and theory. In order to assure that the coding scheme could reliably assess behaviors that 
frequently occur during the task, a pilot study was conducted. The verbal interaction of the dyads performing EPT was recorded and converted into a written transcript. The reliability of the written transcripts was found to be $99 \%$ accurate when double-checked by a separate observer. These written transcripts were used for both the pilot study and the primary investigation (See Appendix B for transcription rules).

In the pilot study, a total of twenty-four transcripts were coded for six behaviors including demands, tutoring, task irrelevance, problem solving, encouragement, and collaborative responsiveness. Segments of the transcript were coded according to their temporal location (beginning, middle, and end of each task). Data that was actually coded was determined by calculating the word count for the task. The sections that were coded were from 10\% - 20\% (beginning), 45\% - 55\% (middle), and $80 \%$ - 90\% (end). It is important to note, however, that the individual statements were not being scored. Instead the score consisted of the overall trends for the segment (beginning, middle, or end) coded using a likert scale.

\section{Pilot Study Reliability}

Two individuals separately coded each transcript allowing percent agreement and kappa for each behavior code to be assessed. Before coding began, each researcher was given a coding manual describing the coding scheme. They then practiced scoring transcripts for several weeks to become familiar with the coding scheme and to resolve any questions related to coding. Kappas were not obtained for collaborative responsiveness and problem solving as an initial low percent agreement indicated a lack of interrater reliability. The other four interactive behaviors had higher reliability. Tutoring had a kappa of .64 (percent agreement $=81.9 \%)$. Task irrelevance had a kappa 
of $.73($ percent agreement $=80.3 \%)$. Dominance had a kappa of .51 (percent agreement $=$ 65.3\%). Encouragement had a kappa of .76 (percent agreement = 93.8\%). The kappas found in the pilot study were adequate but for some behaviors, especially dominance, improved reliability was desired (Landis \& Koch, 1977).

\section{Problems Identified in Pilot Study}

There were several problems found in the pilot study that needed to be taken into consideration. The largest problem dealt with reliability. Even after extensive practice, interrater agreement was not high. Several steps were taken to insure reliability in the present study. First, as reported above, two of the behaviors (collaborative responsiveness and problem solving) were considered unreliable. These behaviors were therefore not included in the present coding scheme. In addition operational definitions for the more reliable codes were problematic. The two codes that had the highest kappas (tutoring and encouragement) were the least frequent while the codes that had higher scores (dominance and task irrelevance) had lower kappas that bordered unacceptable. In order to increase kappas in all domains, the Likert scale rating was abandoned. Instead the present coding scheme analyzed each clause to obtain frequency scores for the given behaviors opposed to the more general ratings.

In addition, the reliability for dominance was especially low (kappa $=.51)$. A possible explanation for this problem deals with one particular aspect of how dominance was operationally defined. Dominance in the pilot study included overt instances of verbal dominance as well as demonstrating more verbosity than one's partner. The overt instances of dominance appeared to be consistently agreed upon while the verbosity aspect of dominance was more subjective and a cause for dispute. In addition, it is not 
clear whether simply talking more than one’s partner actually represents dominant verbal behavior. For example, one partner may not speak much but still be very dominating towards his or her partner. If verbosity is included in the dominance definition, however, the partner who is being dominated by their less talkative partner would score high on dominance even if they did not exert or attempt to exert any control over their partner or the situation. For these reasons, verbosity was not considered as a characteristic of dominance in the present study. Another problem with the definition of dominance was that it only focused on one individuals' behavior. Technically, however, dominance does not occur unless one's partner is submissive. Therefore, in the current analysis the name for these overt behaviors was changed to demands.

Another problem dealt with the frequency that the behaviors occurred. None of the reliably coded behaviors were found to be very frequent during the collaborative interaction on the EPT. After completing and gaining experience coding the verbal behaviors in the EPT during the pilot study, it became apparent that the verbal behaviors were operationally defined in a manner that only detected very extreme occurrences (with the exception of dominance, which was actually too broad as discussed above). These categories were therefore defined differently in the present study to include instances more common in the EPT. In addition, two categories were added to the present coding scheme (read question and answer question) to minimize the number of verbal behaviors that would be placed into the 'other task-related behaviors' category. 


\section{Revised Coding Scheme}

\section{Definitions for Basic Categories of Behaviors}

Based on the pilot study, several changes to coding categories, definitions, and procedures were implemented to form the coding scheme used in the analyses. This revised coding scheme divided behaviors into four major categories as well as three additional categories that were added for descriptive purposes and not included in analyses. The categories are thought to represent interaction styles typical in collaborative problem solving. The constructs were operationally defined to directly reflect the types of behaviors exhibited by older adults performing the Everyday Problems Test. A definition of the major categories, examples, and detailed coding instructions are provided in Appendix C (although the coding manual provides information about macro level coding, only the micro level coding was analyzed in the current study).

Demands. Demands referred to behaviors related to controlling the other participant. It has been speculated that these types of behaviors hinder cooperation and interdependence in marital relationships (Tuites \& Tuites, 1986). This control can occur in different domains. For example, a participant may attempt to control the session, their partner, or the outcome of the task. Therefore, demands were measured by coding verbal behaviors that attempted to control any of these three domains.

Tutoring. Tutoring referred to an individual participant's behaviors directed toward helping their partner. Williams (2001) found that when given a task to solve, children in dyads would take on "teacher" and "learner" roles. It was therefore important to determine if older adults commonly demonstrated tutoring behaviors and whether or not the frequencies of these behaviors depended on the type of task or the abilities of the 
individuals. King (1998) reported that tutoring could be beneficial to both the "teacher" and the "student" as both individuals usually increase their performance level in variety of problem solving situations. This category does not measure the amount of help that is given or the usefulness or quality of the help. Instead, the perceived intent of the behavior is being measured. For example, if the participant offered their partner help and the partner refused to accept the help or the help was not beneficial to the partner's performance, the initiating behavior was still intended to give assistance and would therefore be considered as tutoring. Tutoring behaviors were all task related. In other words, they were intended to help their partner improve performance on the task.

Task Irrelevance. Previous literature examining collaboration in childhood has shown that task irrelevant behaviors during building and balancing tasks are an important factor in collaborative outcome as dyads that display high levels of task irrelevance tend not to benefit as much from the collaboration compared to dyads that display very small amount of task irrelevant behavior (Azmitia, 1988; Cooper, 1980). The task irrelevance category was designed to measure whether or not the participant displayed verbal behavior that was focused on the task at hand, or seemed more interested in discussing things that were not task related. This category coded how much the participant exhibited behavior that was directly intended to complete the task at hand (EPT). If an individual discussed their personal life and the story appeared to be irrelevant to completing the task it would be considered task irrelevance. If the personal information was relevant to the task at hand and directly beneficial to completing the task, however, it would not be considered as task irrelevance. 
Encouragement. This category dealt with behaviors that were encouraging to one’s partner. Noller, Feeney, Bonnell, and Callan (1996) found that being encouraging to one's partner by being supportive and acknowledging the other person's point of view, is an important aspect of conflict resolution among married couples. It could also be inferred that such interaction styles are important in how the couple works together to solve problems. The interactive behaviors considered encouragement in the present study were intended to positively affect how their partner felt about their self, their performance, the situation, or to simply encourage participation in the conversation (both task relevant and irrelevant). Encouragement was not intended to give support to one's partner in terms of completing the task or performance, but was intended to give support concerning how their partner feels about the task, their performance, or the value of their participation.

Descriptive Codes. Three other behaviors were coded for to obtain a better understanding of all the interactive behaviors but have no theoretical significance (read question, answer question, and other). Read question and answer question, for example, simply consists of a participant reading a question verbatim or stating an answer. Behaviors classified as "other" typically included incomprehensible statements that appeared to be related to the task. These three categories of behaviors therefore are more routine, and are believed to contribute less to the collaborative process than the four primary behaviors, which reflect more active behaviors. For example, read questions and answer question consists of simply stating an answer or reading the question verbatim. If the question is paraphrased or the answer is accompanied by an explanation, the behavior 
would have been coded as tutoring. Read question, answer question, and other are not discussed or analyzed further in the present study.

\section{Revised Coding Procedure}

The coding scheme was designed to identify four verbal behaviors. The written transcripts were used to classify behaviors in four major categories: demands, tutoring, task irrelevance, and encouragement. Other behavior categories were created to better describe the entire content of the interaction but were not theoretically relevant or considered in analyses. These categories include reads question, answers question, and other task-related behaviors. Forty random transcripts were chosen to be coded.

Behaviors were coded on an individual level. Therefore the behavior did not have to be shared by both partners, if one partner demonstrated the behavior it was coded for that partner alone. Coding took place on the micro level meaning that each display of verbal behaviors was coded opposed to labeling behaviors for large portions of the transcripts. To obtain these micro level codes, the transcripts were unitized by separating the written statements based on turns or clauses. A turn was defined as a statement that is surrounded by the other participant's verbal behaviors. Clauses consisted of the expression of a complete thought as there could be multiple clauses within a given turn (See Appendix D for additional transcript unitization rules). Twenty percent of the transcripts were unitized by separate individuals and the unitization was found to be 93.9\% accurate (See Appendix E for rules for calculating unitization reliability). Each individual and clause was therefore coded separately although surrounding clauses were used to determine the context of the clause in question. The codes were mutually exclusive so each unit of the transcript received one and only one score. 


\section{Establishing Coding Scheme Reliability}

Coding was completed by one graduate student and two undergraduate students. In order to establish reliability, practice coding was conducted and each of the three individuals would separately code the same transcripts (the transcripts that were used for practice were not among the transcripts examined in the present study). After individually coding the transcript, all three researchers met to discuss any discrepancies found in the coding and clarifications of the operational definitions for the different behaviors were made. In order to insure a high level of interrater reliability, such practice continued until all three researchers consistently unanimously agreed on all of the behavior codes over $80 \%$ of the time.

To assess reliability after practice was completed and the actual coding began, twenty percent of the transcripts were coded separately by two different individuals. The transcripts were then compared and the average kappa was calculated for each of the four behaviors. Task irrelevance was the most reliable of the four behaviors with an average kappa of .90 followed by tutoring (.83). The reliabilities of these codes are considered excellent (Landis \& Koch, 1977). The average kappa for encouragement was .80, while demands had an average kappa of .77. These kappas are considered “substantial” (Landis \& Koch, 1977).

\section{RESULTS}

The current investigation addressed three primary research questions. First, did participants in the current study exhibit similar levels of interactive behaviors during collaboration? Specifically, did interactive behaviors vary by several factors including problem solving performance order (individual vs. collaborative performance first), 
partner familiarity (spouse vs. unfamiliar stranger), or participant sex? This aim examined the extent to which participants displayed behaviors including demands, tutoring, task irrelevance, and encouragement. Second, to what extent did individual characteristics predict interactive behaviors? This question considered the impact of similarities and differences between the partners in cognitive ability, collaborative expectations, participant sex, and personality. It was then determined whether or not these characteristics were predictive of participants' interactive behaviors. The third research aim examined how the dyadic interactive behaviors related to the outcome (i.e., performance) of the collaboration. In addition, exploratory analyses were conducted to determine whether the proportion or effect of behaviors varies when dividing the task into three temporal session segments (beginning, middle, and end).

Preliminary Analyses

Descriptive Analyses

All transcripts were qualitatively coded to determine the proportion of interactive behaviors observed in the collaborative completion of the Everyday Problems Test (EPT). The interactive behaviors under investigation in the current analyses included demands, tutoring, task irrelevance, and encouragement.

To obtain descriptive information about behaviors that did not fit into these four categories ( $17 \%$ of observed behaviors), three additional categories of behaviors were created including read question, answer question, and other (i.e., task related behaviors that did not fit into another category). Frequencies for all behaviors are depicted in Table 3. 


\section{Inter-relationships Between Variables}

Correlations were obtained for the four interactive behaviors to assess the degree of overlap between the interactive behavior coding categories (See Table 4). In general, correlations were not highly related suggesting that the coding scheme did examine distinct categories; however, some interactive behaviors were significantly related. For both men and women, there was a significant, negative relationship between tutoring and task irrelevance. This relationship suggests that individuals focused on the task were more likely to display behaviors intended on assisting their partner with the task. There was also a significant, negative relationship between tutoring and encouragement for both men and women. These correlations suggest that an individual assumed either a tutoring or an encouraging role instead of displaying high levels of both tutoring and encouragement. In addition, men's and women’s task irrelevance was significantly and positively related, reflecting that as one partner discussed something unrelated to the task, it was common for their partner to respond in kind. These correlations suggest that the coding categories are distinct and are related to each other in an interpretable fashion.

\section{Primary Analyses}

The next set of analyses address the primary research aims. First, a series of between-subjects analysis of variance (ANOVA) tests were performed to determine whether the proportion of interactive behaviors was equivalent across groups or if the behaviors differed based on performance order, partner familiarity, or participant sex. Next, four hierarchical regressions (one for each behavior) were conducted to determine predictors of demands, tutoring, task irrelevance, and encouragement. Following, a hierarchical regression was also conducted to determine the relationship between the four 
interactive behaviors and collaborative performance. Finally, the same basic analysis techniques were used in an exploratory manner to examine the role that temporal task segments (beginning, middle, and end) played in the three primary research questions. Unless otherwise noted, an alpha level of .05 was used for all analyses.

\section{Group Differences in Interactive Behaviors}

The first aim of the current study was to determine if participants exhibited similar levels of interactive behaviors during collaboration. A series of between-subjects ANOVA tests were conducted to test for basic group differences and to determine whether the levels of interactive behaviors varied based on performance order (collaborative versus individual performance first), partner familiarity (paired with spouse versus stranger) or participant sex. All possible interactions were also tested. Thus four 2 (performance order: collaborative and individual performance first) X 2 (partner familiarity: paired with spouse and paired with a stranger) X 2 (sex: male and female) ANOVA tests were conducted, one for each interactive behavior.

\section{Demands}

The analyses suggested a significant difference in the proportion of demands based on partner familiarity ( $F=3.96, p<.05$; see Table 5 for ANOVA results), indicating that individuals who are familiar with each other (married) exhibited a larger proportion of demands when collaborating on the EPT compared to individuals who did not know each other. There were no significant differences, however, in demands based on participant sex and performance order. 


\section{Tutoring}

Analyses examining general differences in tutoring behaviors did not reveal significant differences between the familiar and unfamiliar conditions, performance order, or participant sex for the proportion of tutoring behaviors exhibited (See Table 6).

\section{Task Irrelevance}

There was a significant main effect for performance order $(F=17.41, p<.01)$ and partner familiarity $(F=8.94, p<.01)$ when examining task irrelevance. Individuals who participated in the collaborative session first, engaged in more task irrelevance compared to individuals who participated in the individual session first. Individuals who worked with an unfamiliar partner demonstrated higher levels of task irrelevance compared to individuals who worked with their spouse (See Table 7).

\section{Encouragement}

There were no significant differences found between the familiar and unfamiliar conditions, performance order, or participant sex for displays of encouragement (See Table 8).

\section{Predicting Interactive Behaviors}

The second aim of this investigation was to determine whether individual characteristics predicted interactive behaviors. To address this question, a series of hierarchical regressions were conducted. Step one included experimental design variables (performance order and partner familiarity). Step two included individual characteristics: participant sex, collaborative expectations, extroversion, openness, and cognitive ability. Step three consisted of partner characteristics including partner collaborative expectations, partner extroversion, partner openness, and partner cognitive 
ability. The hierarchical regression technique was utilized to determine whether self and partner characteristics were predictive of interactive behaviors after accounting for variance explained by design factors (performance order and partner familiarity). Analyses were conducted separately for each interactive behavior.

\section{Demands}

Results of the hierarchical regression conducted for demands, indicated that neither the full model nor any of the individual steps were significant predictors of demands (See Table 9). The full model only predicted $11 \%$ of the variance. Partner familiarity was a significant individual predictor of demands ( $\beta=.22, p<.05)$. Congruent with previous analyses, there was a positive relationship between the partner familiarity variable and the proportion of demands.

\section{Tutoring}

Neither step one (design variables) nor step two (individual characteristics) significantly predicted tutoring behaviors (See Table 10). The individual predictors and change in $R^{2}$ were also not significant in the first two steps. The third step, however, proved to be valuable in predicting tutoring behaviors $\left(\Delta R^{2}=.17, p<.01\right)$. As a result, once step three was included, the full model was significant, explaining $25 \%$ of the variance in tutoring $(p<.05)$. Partners' cognitive ability was a significant predictor of tutoring behaviors ( $\beta=-.43, p<.01$ ). Partners' cognitive ability was negatively related to tutoring indicating that individuals exhibited less tutoring when their partner was cognitively, highly competent. 


\section{Task Irrelevance}

Step one was a significant predictor of task irrelevance explaining $25 \%$ of the variance $(p<.01$; See Table 11). Step two and three, however, did not significantly contribute to the predictive utility of step one, as there were no significant changes in $R^{2}$. Both individual predictors in step one (performance order; $\beta=.40, p<.01$ and partner familiarity; $\beta=-.29, p<.01$ ) were significant predictors. Consistent with previous results, individuals in the unfamiliar condition and individuals who performed the EPT collaboratively first were more likely to exhibit task irrelevance.

\section{Encouragement}

Neither step one (design variables) nor step two (individual characteristics) significantly predicted encouragement (See Table 12). The third step, however, proved to be useful in predicting encouragement $\left(\Delta R^{2}=.17, p<.01\right)$. As a result, once step three was included, the full model was significant, explaining $26 \%$ of the variance in encouragement $(p<.05)$. Partners' cognitive ability was significantly predictive of encouragement $(\beta=.37, p<.01)$. The relationship between partners' cognitive ability and encouragement indicated that as individuals were more likely to encourage their partners to participate in the collaborative problem solving when their partner had high levels of cognitive ability.

\section{Predicting the Collaborative Outcome}

The third aim of the study examined how design factors, self, and partner behaviors predicted the collaborative outcome. The dependent variable (collaborative outcome) consisted of a difference score, which was obtained by subtracting the participants’ individual score from their collaborative score. A difference score was used 
so that the collaborative outcome would reflect how well participants did in the collaborative session in relation to their individual performance. Individual baseline performance was therefore controlled for as the degree that individuals improved or declined was examined instead of their total score (Hofland, Willis, \& Baltes, 1981). A positive difference score indicated that the participant's score in the collaborative setting was higher than his or her score in the individual setting while a negative score demonstrated that the participant's score in the collaborative setting was lower than his or her individual score. The average difference score was 1.32 indicating that overall, within this sample, participants tended to perform better in the collaborative setting (range $=-16.13$ to $22.58 ; S D=8.38)$.

To assess whether the interactive behaviors were predictive of the collaborative outcome, a hierarchical regression analysis was conducted (See Table 13) to determine if an individuals interactive behaviors as well as the interactive behaviors of his or her partner accounted for any variance beyond what was explained by design factors (performance order and partner familiarity condition). Step one included design factors. The second step in the regression included an individual's four interactive behaviors while the third step included partner’s four interactive behaviors.

Step one was a significant predictor of collaborative outcome explaining $8 \%$ of the variance $(p<.05)$. Partner familiarity was a significant individual predictors of collaborative gain $(\beta=.23, p<.05)$. Step two (individuals' interactive behaviors) did not significantly contribute to the predictive utility of the model. In addition, none of the individual characteristics in step two were predictive of difference scores. Step three, however, added significantly to the predictive utility of the model, $\left(\Delta R^{2}=.16, p<.01\right)$. 
By including step three, the full model explained $31 \%$ of the variance in the collaborative outcome ( $p<.01$ ), although none of the individual predictors in step three had significant predictive utility. Partner familiarity and performance order were significant individual predictors when examining the full model $(p<.01)$.

\section{Exploratory Analyses}

\section{Beginning, Middle, and End Session Segments}

Previous research examining the process of collaboration has found that types of behaviors exhibited during collaboration may differ from the beginning of the collaborative session compared to the end (Gould, Kurzman, \& Dixon, 1994). For exploratory purposes, it was therefore determined whether the interactive behaviors differed in regard to the segments in which they occurred (i.e., the beginning, middle, and end of the task). Table 14 depicts the proportion of behaviors exhibited at each segment broken down by order, familiarity, and sex. The beginning segment consisted of EPT items 1-5, middle consisted of items 6-9, and end consisted of items 10-14. Only findings demonstrating main effects for segment or segment effects that differ from the primary analyses are reported.

Group Differences in Interactive Behaviors at Beginning, Middle and End

A series of repeated measures ANOVA tests (one with each of the four interactive behaviors as dependent variables) were conducted to determine the role of segment in how interactive behaviors varied by performance order, partner familiarity, and participant sex. Between-subjects variables included performance order, partner familiarity, and participant sex while the within-subject factor included segment (beginning, middle, and end). Thus four 2 (performance order: collaborative and 
individual performance first) X 2 (partner familiarity: paired with spouse and paired with a stranger) X 2 (sex: male and female) ANOVA tests were conducted using the three interactive behavior scores obtained during the temporal segments as the dependant variables.

Demands

Accounting for segments did not contribute to a greater understanding of demands, as there was not a significant main effect. There were also no interactions between segment and partner familiarity, performance order, or participant sex (See Table 15).

\section{Tutoring}

There was a significant within-subjects effect for segment when examining tutoring behaviors $(F=9.70, p<.01)$. Post hoc mean comparisons were examined. These comparisons indicated that the proportion of tutoring behaviors displayed during the beginning segment was significantly lower than the proportion of tutoring behaviors exhibited during the middle segment $(F=16.92, p<.01)$ and during the end segment $(F$ $=12.04, p<.01$ ). The proportion of tutoring behaviors displayed during the middle segment did not significantly differ from tutoring during the end segment (See Table 16; see Figure 1).

\section{Task Irrelevance}

There was a significant segment by partner familiarity interaction for task irrelevance $(F=3.57, p<.05)$. Follow-up mean comparisons revealed that individuals in the familiar and unfamiliar condition did not differ in the proportion of task irrelevance for the beginning and end segments. Participants in the unfamiliar condition, however, 
displayed a significantly higher proportion of task irrelevance in the middle segment compared to individuals in the familiar condition $(F=16.05, p<.01$; see Figure 2). Main effects were also found for partner familiarity, performance order, and participant sex consistent with previous findings. However, the effect for participant sex was only a trend in research question one. After including temporal segments, it was found that women exhibited more task irrelevance than men (See Table 17).

\section{Encouragement}

Accounting for segments did not contribute to a greater understanding of encouragement, as there was not a significant main effect of segment. There were also no interactions between segment and partner familiarity, performance order, or participant sex (See Table 18).

\section{Predicting Interactive Behaviors}

Additional hierarchical regression analyses were conducted to determine if performance order, partner familiarity, individual characteristics, or partner characteristics were differentially predictive of interactive behaviors during the beginning, middle, and end of the task. Step one of the regression included partner familiarity and performance order, step two included individual characteristics, and step three included partner characteristics. In general, findings were consistent with those previously reported. Only findings that differ from the original analyses are mentioned.

\section{Demands}

Demands, which were observed the least when examining behaviors throughout the EPT, showed similar findings in the middle and end segments. For the beginning 
segment, on the other hand, step one (performance order and partner familiarity) was a significant predictor of demands, accounting for $11 \%$ of the variance (See Table 19). Tutoring

Tutoring maintained the same pattern for the beginning segment that was found when examining tutoring throughout the entire EPT. Tutoring during the middle segment, however, showed no significant predictors for any of the three steps or the full model. The end section revealed similar results as the beginning but the third step was a trend and not significant (See Table 20).

\section{Task Irrelevance}

Task irrelevance had the same pattern for beginning, middle, and end as previously found when examining predictors of task irrelevance without accounting for segment. Step one had the most predictive utility with little variance accounted for in steps two and three for beginning, middle, and end. Step one was less predictive in the end, however, resulting in the full model not significantly predicting task irrelevance (See Table 21).

\section{Encouragement}

Encouragement had the same pattern across the three segments that were found when examining encouragement within the entire task. The first two steps accounted for very little variance but step three (partner characteristics) accounted for more variance (See Table 22).

\section{Predicting Collaborative Outcome}

A hierarchical regression was conducted to determine whether behaviors exhibited during specific segments were predictive of the collaborative outcome (See 
Table 23). As partner interactive behaviors contributed significantly to predicting the collaborative outcome and individual behaviors were not predictive, only partner behaviors were included in this analysis. Step one included partner familiarity and performance order. Step two included the proportion of partner demands, tutoring, task irrelevance, and encouragement for the beginning segment. Step three included the proportion of partner demands, tutoring, task irrelevance, and encouragement for the middle segment. Step four included the proportion of partner demands, tutoring, task irrelevance, and encouragement for the end segment.

Step one was a significant predictor of collaborative outcome explaining $8 \%$ of the variance $(\mathrm{p}<.05)$. Steps two and four (partner behaviors during the beginning and end) did not significantly contribute to the predictive utility of the model. Step three (partner behaviors during the middle of the task), however, did significantly contribute to the predictive utility of the model $\left(\Delta \mathrm{R}^{2}=.16, \mathrm{p}<.01\right)$.

\section{DISCUSSION}

\section{Summary of Study}

The current study examined interactive behaviors exhibited by older adults performing the Everyday Problems Test (EPT) individually and collaboratively. The sample consisted of twenty older adult dyads comprised of spouses (familiar condition) and twenty older adult dyads comprised of strangers (unfamiliar condition). Betweensubjects factors included partner familiarity and performance order. The order that individuals first performed the task (individually versus in a collaborating dyad), was counterbalanced so that half of the sample completed the task individually first and half of the sample completed the task collaboratively first. Within-subjects factors included 
individual versus collaborative performance and temporal coding segments (beginning, middle, and end) within the collaborative problem-solving session. The interactive behaviors examined included demands, tutoring, task irrelevance, and encouragement. A pilot study was conducted to strengthen the operational definitions of the coding constructs and to determine procedural changes necessary to establish inter-rater reliability.

Three primary research questions as well as exploratory research aims were examined in the current study. The first primary research question examined the extent to which the interactive behavior variables differed based on participant sex, performance order, and partner familiarity. The second primary research question determined whether design factors (partner familiarity and performance order), individual characteristics, and partner characteristics were predictive of the interactive behaviors. The third primary research question investigated whether the interactive behaviors were predictive of the collaborative outcome (the extent that an individual's collaborative score differed from their score when performing the EPT alone). Exploratory analyses determined if accounting for temporal segment (beginning, middle, and end) within collaborative performance on the EPT added any clarity to the three primary research questions (See Table 24 for a summary of results).

\section{Summary of Results \\ Differences in Interactive Behaviors}

As expected, the proportion of interactive behaviors varied based on performance order and partner familiarity, however, none of the interactive behaviors varied by participant sex. No group differences in the proportion of tutoring and encouragement 
were found, however, partner familiarity differences were found when examining demands and task irrelevance. Familiar dyads displayed a higher proportion of demands and unfamiliar dyads exhibited a higher proportion of task irrelevance. The performance order effect was found for task irrelevance as individuals who performed in the collaborative problem-solving session first were engaged in a higher proportion of task irrelevance.

\section{Predictors of Interactive Behaviors}

In addressing the second specific aim of this study, it was found that performance order, partner familiarity, individual characteristics, and partner characteristics were predictive of some of the interactive behaviors. None of the factors examined predicted demands. For tutoring, partner characteristics were very predictive, largely due to the predictive utility of partner's g score (a composite score reflecting general cognitive ability), which was negatively related to tutoring. Performance order and partner familiarity were the only important predictors of task irrelevance. Much like tutoring, the full model was a significant predictor of encouragement, mainly due to the predictive value of partner's g score. Unlike tutoring, however, partner's g score was positively related to encouragement.

\section{Predictors of Collaborative Outcome}

The third aim of the current study examined the utility of design factors (performance order and partner familiarity), individual interactive behaviors, and partner interactive behaviors in predicting the collaborative outcome (performance). Performance order and partner familiarity were significant predictors of difference score as performing individually first as well as being in the familiar condition were associated 
with collaborative gain. In addition, the group of interactive behaviors exhibited by one's partner was also significantly predictive of the collaborative outcome although none of the individual behaviors were significant individual predictors.

\section{Exploratory Analyses}

Exploratory analyses were conducted to investigate the effect of temporal segments (beginning, middle, and end). It could then be determined whether behaviors were uniform across the tasks or differed in frequency or predictive utility at different segments. Findings suggested that tutoring behaviors were more prevalent during the middle and end of the task compared to the beginning. In addition, for task irrelevance, there was a segment by partner familiarity interaction as it was determined that unfamiliar dyads displayed a higher proportion of task irrelevance during the middle of the task compared to familiar dyads. In regard to the collaborative outcome, results suggested that partners' interactive behaviors during the middle of the task were most predictive of the difference score (See Table 24 for a summary of results).

\section{Implications}

\section{Differences in Interactive Behaviors}

The finding that strangers exhibited a higher proportion of task irrelevance and a lower proportion of demands compared to married couples could represent adaptive strategies used by both familiar and unfamiliar collaborating dyads. For example, it may be necessary for unfamiliar dyads to discuss issues not particularly related to solving the task at hand to better understand each other's past experiences, strengths, and weaknesses so that each member of the dyad can contribute to the task more efficiently. If an unfamiliar dyad was working on a task related to following a recipe, for example, it 
would be beneficial to know if either of the individuals was an experienced cook and accustomed to following a recipe. Such past experiences may allow certain individuals to be more skilled at performing certain types of everyday tasks than less experienced individuals. It may be necessary, then, for unfamiliar dyads to engage in a certain amount of behaviors unrelated to the actual solution of the task in performance order to understand how their partner's strengths may compensate for their own weaknesses. Similarly, individuals in unfamiliar dyads may display less demands because they would not be sure whether they are more competent within a given domain compared to their partner. By exhibiting demands when working with an unfamiliar partner, one could be decreasing their partner's potential contribution to the task without confirming their ability level.

Married couples, on the other hand, may utilize different strategies when approaching an everyday task compared to the unfamiliar dyads. Long-term married couples (such as the familiar dyads in this study) share a long history and each individual is probably very familiar with the capabilities of their spouse and their self. Due to this increased understanding of the strengths and weaknesses of each individual, it would not be beneficial to engage in frequent acts of task irrelevance. In fact, more frequent displays of demands may contribute to successful completion of the task. For example, if an individual immediately realizes that they are highly competent in the domain of a certain task and that their spouse's strengths are not in that area, he or she may demonstrate demanding behavior by delegating responsibility and providing instruction for that particular task. As a result, each member of the couple would benefit from the specific expertise of his or her spouse. It was therefore not surprising that partner 
familiarity was the only significant predictor of demands, while partner familiarity and performance order were the two strongest predictors of task irrelevance.

It is quite possible that the degree to which familiar and unfamiliar dyads display demands and task irrelevance may be beneficial to both types of dyads. It is also possible, however, that despite potential benefits that may exist for familiar dyads to display more demands and for unfamiliar dyads to display more task irrelevance, the differences found for these interactive behaviors could have nothing to do with problem solving strategy. An alternative explanation would be that individuals are simply following social norms that suggest people who do not know each other should attempt to be polite and on their best behavior. Participants in unfamiliar dyads may therefore refrain from demanding or controlling behaviors while also showing interest in their partner through task irrelevance. Dyads involved in a long-term marriage, however, may not censor their behavior as much due to the long history shared with their collaborative partner. Even if the differences in behaviors exhibited are a result of social norms instead of strategy implementation, it is still possible that demands and task irrelevance are differentially beneficial to the performance of familiar and unfamiliar dyads.

The performance order effect that was found for task irrelevance (participants who performed the collaborative session first engaged in a higher proportion of task irrelevance) could suggest that as familiarity with the task increases, so does the proportion of task relevant behaviors. Individuals who performed the individual session first may have brought a greater understanding of the tasks they were to perform as well as an understanding of possible problems they might have with everyday tasks. These individuals (especially participants in the unfamiliar condition) may therefore not need to 
engage in as much task irrelevance to explore their partner's strengths and weaknesses. The participants may have developed an understanding of their strengths and weaknesses during the individual session and could therefore more readily make more problemfocused suggestions or requests.

\section{Predictors of Interactive Behaviors}

The idea that the degree to which an individual contributes during a collaborative situation depends not only on their cognitive abilities but also on the cognitive abilities of their partner is further supported when examining predictors of interactive behaviors. For example, the cognitive ability of one's partner was negatively related to the amount of tutoring and positively related to the amount of encouragement an individual displayed. If someone was collaborating with a partner who had a high level of competence, they were less likely to tutor their partner and more likely to encourage participation. On the other hand, when working with an individual with lower cognitive ability, one was more likely to tutor and less likely to encourage more participation or feedback. These findings further support the idea that many factors are related to how an individual behaves in a collaborative setting and that individuals adjust their strategy based on the characteristics of their partner.

These findings also support assertions by Vygotsky that describes how individuals working together on a task often differ in their ability level. According to Vygotsky's theory, the more skilled individual will assist the lesser skilled individual, resulting in an enhancement of the lesser skilled individual's cognitive performance (Tudge, \& Rogoff, 1999). The important role of the cognitive ability of one's partner in predicting tutoring and encouragement could be interpreted as support for this theory. For example, the 
finding that there was a negative relationship between tutoring and the composite cognitive score of one's partner suggests that when an individual was working with a less skilled partner, he or she was more likely to exhibit tutoring behaviors than when working with a more skilled partner. Conversely, when an individual's partner had high cognitive ability, the individual was more likely to encourage his or her partner to participate. These relationships suggest that more skilled individuals were more likely to tutor their partner and that their partner was more likely to encourage their participation. These communication patterns compliment Vygotsky's theory that a more skilled individual enhances his or her partner's cognitive ability at a given task.

Not only do these findings correspond with Vygotsky's theory, they also complement previous findings in this data set. Margrett (1999) found that individuals who were more impaired in instrumental activities of daily living had a greater desire to collaborate on tasks similar to those performed in the EPT. The finding in the current study that the cognitive ability of one's partner is especially predictive of encouragement and tutoring, adds to this understanding. Whereas Margrett (1999) found that low individual ability was influential in wanting to collaborate with others, the current analyses suggest that the ability of one's partner is also influential in the collaborative process.

\section{Predictors of Collaborative Outcome}

Thus far it has been demonstrated that many factors are important in predicting what behaviors are exhibited during a collaborative task. It is essential, however, to not only understand predictors of the collaborative process, but to also understand how this process relates to the outcome of collaboration. As expected, partner familiarity was a 
significant predictor of the collaborative outcome. Another significant predictor of the collaborative outcome was performance order as performing the EPT alone first was associated with more of a gain in the collaborative condition. It is possible that performing the EPT individually first allows one to become familiar with the task and to realize the weaknesses related to this type of task and to therefore be more efficient when working with a partner.

Performance order may have also influenced one’s difference scores in other ways. For example, if an individual performs individually first and scores below average on the EPT, odds are this individual would be paired with a higher performing partner and increase a great deal. This pairing would result in a substantial difference score indicating that collaborative performance was beneficial. On the other hand if the same individual worked with a partner first, he or she may not perform as poorly later during the individual condition due to the carry over of strategies or assistance provided in the collaborative session to the individual session. When performing in this order, the same individual would appear to have received less of a benefit from collaboration. Findings by Margrett (1999) using the same data (but a larger sample) suggest that it is possible that strategies and assistance provided in the collaborative session may in fact influence one's individual performance later. For example, it was found that individuals who collaborated with their spouse first performed better in the individual condition later.

Partners' behaviors were also predictive of the collaborative outcome although no single individual partner behavior was a significant predictor. In addition, the exploratory analyses suggest that partners' behaviors during the middle of the task were most predictive of the collaborative outcome. These findings suggesting that behaviors 
exhibited by one's partner are predictive of how much someone benefits (or declines) during collaboration are an important step in understanding factors related to the collaborative performance.

\section{Limitations and Future Directions}

Several caveats should be noted when interpreting results from the current study. First, a subsample of a larger study was used for the current study so further research must be conducted to determine if similar findings are observed in larger samples. A common standard for the number of predictors used in a regression compared to the sample size is: $(50+6 *$ the number of predictors; Tabachnick \& Fidell, 2001). According to this equation, it would have been ideal to have 30 more participants. The relatively small sample compared to the number of predictors could result in difficulty identifying small effects (Tabachnick \& Fidell, 2001). To assure that the sample was indeed large enough to detect meaningful effects, post hoc power analyses were conducted. It was determined that ample power was present for detecting medium $(f>$ .25 ; power $=.66)$ and large $(f>.25 ; 1.0)$ effects in all primary analyses conducted (Cohen, 1977). Although the sample may not be large enough to detect small effects, the sample size is relatively large compared to some other studies examining the collaborative interaction ( $N=40$; Gould \& Dixon, 1993). In addition, due to the fact that the sample consisted of high-functioning older adults, it is unknown whether the collaborative process or outcome would be equivalent among older adults with more functional impairments.

There are also issues related to data dependency that exist when analyzing dyadic data such as in the present study. Since individuals are working together and actively 
affecting one another's interactions, partners influence the individual behaviors that were coded. Such dependency issues are an inherent aspect in collaboration research because if partners did not influence each other's behavior or performance in some way, there would be no effect of collaboration. Stevens (1996) describes how intraclass correlations are the appropriate method of detecting the severity of data dependency. If these intraclass correlations indicate a dependency problem, chances of committing a Type I error is substantially increased and it is suggested that group data is assessed instead of individual data (Stevens, 1996). Intraclass correlations were conducted to determine the degree of dependency between partners' interactive behaviors while performing the EPT (See Table 25). Except for task irrelevance, intraclass correlations between partners' interactive behaviors were low. These low intraclass correlations combined with the small group sizes lessens the risk of committing a Type I error (Stevens, 1996) when analyzing the interactive behaviors on an individual level. Although it appears that there were dependency issues related to task irrelevance, all primary analyses were still conducted on the individual level. The focus of the current study was on identifying how partners affected each others' behaviors and scores. Conducting analyses at the dyadic level would not allow for these relationships to be examined. One possible alternative that allows for analyses to be conducted at the dyadic level while also comparing partners, is to analyze the data with a repeated measures analysis of variance (ANOVA) using sex as a within-subjects variable (e. g., Smith, Gallo, Goble, Ngu, \& Stark, 1998). Such analyses were conducted to assure that dependency of data did not account for the differences found when examining behavior frequencies. The results showed similar findings as the original analyses. 
Another limitation to the current study, deals with the task. Although the EPT closely resembles everyday problems that older adults might face, it is unknown whether older adults collaborate on these types of tasks or if the collaborative process is the same when not in a laboratory setting. In addition, the coding scheme used may be limited to assessing interactive behaviors in similar types of problem solving tasks. Although the constructs under investigation (demands, tutoring, task irrelevance, and encouragement) are broad constructs that could apply to most collaborative settings, the behaviors were operationally defined in the coding manual to represent how these constructs were thought to be represented in the EPT. Applying the coding scheme to other types of tasks may require slight adjustments in the operational definitions of interactive behaviors so that coding would identify unique ways these constructs are demonstrated in different contexts.

\section{Conclusions}

The present study sheds light on the process of collaboration among older adults performing everyday problems. Several factors that are important in determining what behaviors are displayed during collaboration were discovered. In addition to determining how these behaviors vary across different contexts (i.e., familiar dyads and unfamiliar dyads) and what individual and partner characteristics were predictive of interactive behaviors. Results suggested that whether an individual performs better in a collaborative setting than in an individual setting was predicted by the behaviors exhibited by one’s partner. Determinants of partner behaviors, however, include a variety of situational attributes (i.e., performance order and partner familiarity) as well as partner characteristics such as the cognitive ability of one's partner. These findings 
indicate that the collaborative process is truly interactive and dependent on many factors as the behaviors displayed by an individual as well as the gain received from the collaborative experience are predicted by partner characteristics instead of individual characteristics. These findings also suggest that an individual may display very different behaviors depending on the characteristics of his or her partner.

The current study also adds to the literature by describing how the temporal segments of a task may be composed of a variety of behaviors and may also be differentially important. Gould, Kurzman, and Dixon (1994) examined verbal behaviors displayed during the beginning and end of a collaborative story telling task. It was determined that older adult married couples displayed more strategy related discussion at the end of the recall task while unfamiliar older adult dyads displayed more social related discussion at the end of the task. The current study similarly examined different segments of the EPT and also included the middle segment of the task. Similar to Gould, Kurzman, and Dixon (1994), the amount of social behaviors (task irrelevance) exhibited did vary based on segment. Unlike findings reported by Gould, Kurzman, and Dixon (1994), however, task irrelevance did not increase at the end of the task. Instead, there was an interaction as the task irrelevance displayed by unfamiliar dyads peaked during the middle segment while task irrelevance exhibited by familiar dyads was at it's lowest during the middle segment. One plausible explanation for these different findings could be contributed to the different tasks. Similar to Gould, Kurzman and Dixon’s (1994) finding of increased strategy discussion in the later segment of the task, the current study found that the proportion of tutoring behaviors were higher in the middle and end segments than during the beginning of the task. The results also indicated that the middle 
segment of the task seemed to be the most influential as partner behaviors during this segment were predictive of collaborative gain. Perhaps the beginning of the task typically consists of becoming more familiar with the task itself and/or one's partner. It is also possible that most dyads had developed an effective collaborative pattern by the end of the task. The middle may therefore be predictive because during this segment, more effective dyads have established an efficient collaborative pattern while less effective dyads are still attempting to discover how to work together efficiently. A possible alternative explanation, however, could be that the varying item domains and item difficulties on the EPT could have lead to certain behaviors being more prevalent. It is therefore possible that item characteristics could have been responsible for these findings instead of temporal segments. The fact that parallel forms were used, however, does bring this alternative explanation into question since the actual items were different for half of the sample.

Another contribution made by the current study deals with the process and the product of collaboration. Research related to collaboration typically studies either the product (the outcome or how much individuals gain from collaborating) or the interactive process is examined. Important aspects of the process of collaboration include interactive behaviors, individual's collaborative preferences, goals, and strategies. The current study examined both the collaborative process (interactive behaviors) and how the process related to the collaborative product (performance). The process was linked to the product as it was determined how interactive behaviors predict the extent that individuals experience a gain or loss in performance through collaboration. This link between the 
process of collaboration and the product of collaboration in older adults performing everyday problem-solving tasks has received little attention in previous research.

The current study has therefore contributed to the literature on collaboration among older adults by examining the interactive process of collaboration as well as how this interactive process relates to the collaborative outcome. There is a need for future research to examine how the interactive process of collaboration may differ based on the type of task. It can then be determined how the interactive process relates to the collaborative outcome in such tasks. Research should also attempt to better determine what specific types of tasks older adults actually chose to collaborate on in a nonlaboratory setting. 


\section{REFERENCES}

Anderson, J. \& Roenberg, J. (1995). Recall suffers from collaboration: Joint recall effects of friendship and task complexity. Applied Cognitive Psychology, 9, 199-211.

Anderson, J. \& Roenberg, J. (1996). Collaboration and memory: Effects of dyadic retrieval on different memory tasks. Applied Cognitive Psychology, 10, 171-181.

Azmitia, M. (1988). Peer interactions and problem solving: When are two heads better than one. Child Development 59, 87-96.

Azmitia, M. \& Montgomery, R. (1993). Friendship, transactive dialogues, and the development of scientific reasoning. Social Development 2 (3), 202-221.

Baltes, M. (1997). Coping with age. World Health 50, $10-12$.

Baltes, P. \& Baltes, M. (1998). Savoir vivre in old age. National Forum 78, 13 -19.

Berg, C. A., Johnson, M. S., Meegan, S. P., Strough, J. (2003). Collaborative problem solving interactions in young and old married couples. Discourse Processes, 15 (1), 33-58.

Berg, C. A., Strough, J., Calderone, K. S., Sansone, C., \& Weir, C. (1998). The role of problem definitions in understanding age and context effects on strategies for solving everyday problems. Psychology and Aging, 3 (1), 29-44.

Brandstatter, H. \& Farthofer, A. (1997). Personality in social influence across tasks and groups. Small Group Research, 28, 146 - 163.

Brown, T. (1999). Why Vygotsky? The role of social interaction in constructing knowledge. In P. Lloyd (Ed.) \& C. Fenyhough (Ed.), Lev Vygotsky: Critical assessments (pp. 57-66). New York: Routledge. 
Burgio, L., Burgio, K., Engel, B., Tice, L. (1986). Increasing distance and independence of ambulation in elderly nursing home residents. Journal of Applied Behavior Analysis, 19, 357 - 366.

Clements, R. \& Swensen, C. (2000). Commitment to one's spouse as a predictor of marital quality among older couples. Current Psychology, 19, 110 - 120.

Cohen, J. (1977). Statistical power analysis for the behavioral sciences. New York: Academic Press.

Collings, P. (2000). If you got everything its good enough: Perspectives on successful aging in a Canadian Inuit community. Journal of Cross Cultural Gerontology, 16, 127-155.

Cooper, C. (1980). Development of collaborative problem solving among preschool children. Developmental Psychology, 16, 433-440.

Costa, P. T \& McCrae, R. R. (1992). Revised NEO personality inventory and the NEO five factor model. Odessa, FL: Psychological Assessment Resources Inc.

Costa, P. T. \& McCrae, R. R. (1995). Solid grounds on the wetlands of personality: A reply to Block. Psychological Bulletin, 117, 216-220.

DeLisi, R. \& Goldbeck, S. L. (1999). Implications of Piagetian theory for peer learning. In A. M. O’Donnell (Ed.) \& A. King (Ed.), Cognitive perspectives on peer learning (pp. 3-38). Hillsdale, NJ: Erlbaum.

Dixon, R., \& Bäckman, L. (1995). Compensating for psychological deficits and declines: Managing losses and promoting gains. Mahwah, NJ, Lawrence Erlbaum Associates Inc. 
Dixon, R. \& Gould, O. (1998). Younger and older adults collaborating on retelling everyday stories. Applied Developmental Science, 2, 160 -171.

Driskell, J., Mullen, B. (1990). Status, expectations, and behavior: A meta-analytic review and test of the theory. Personality and Social Psychology, 16, 541 -553.

Ekstrom, R. B., French, J. W., Harman, H. H., \& Derman, D. (1976). Kit of factorreferenced cognitive tests (Rev. Ed.), Princeton, NJ: Educational Testing Service.

Fagot, B. I. \& Gauvain, M. (1997). Mother-child problem solving: Continuity through the early childhood years. Developmental Psychology, 33 (3), 480-488.

Fuchs, L., Fuchs, D., Hamlett, C., \& Karnes, K. (1998). High-achieving students’ interactions and performance on complex mathematical tasks as a function of homogeneous and heterogeneous pairings. American Education Research Journal 35, $227-267$.

Goldbeck, S. \& Sinagra, K. (2000). Effects of gender and collaboration on college students’ performance on a Piagetian spatial task. Journal of Experimental Education 69, 22 - 36.

Gould, O., \& Dixon, R. (1993). How we spent our vacation: Collaborative storytelling by young and old adults. Psychology and Aging, 8, 10-17.

Gould, O., Kurzman, D., Dixon, R. (1994). Communication during prose recall conversations by young and old dyads. Discourse Processes, 17, 149-165.

Harris, M. (1990). Effects of interaction goals on expectancy confirmation in a problem solving context. Personality and Social Psychology Bulletin 16, 521 - 530. 
Heckhausen, J. (1999). Balancing for weakness and challenging developmental potential: A longitudinal study of mother-infant dyads in apprenticeship interactions. In P. Lloyd (Ed.) \& C. Fenyhough (Ed.), Lev Vygotsky: Critical assessments (pp. 81 -100). New York: Routledge.

Hofland, B. F., Willis, S. L., \& Baltes, P. B. (1981). Fluid intelligence performance in the elderly: Intraindividual variability and conditions of assessment. Journal of Educational Psychology, 73, 573-586.

Hogan, D. M. \& Tudge, J. R. (1999). Implications of Vygotsky’s theory for peer learning. In A. M. O’Donnell (Ed.) \& A. King (Ed.), Cognitive perspectives on peer learning (pp. 39-66). Hillsdale, NJ: Erlbaum.

Hollingshead, A. B. (1998). Retrieval processes in transactive memory systems. Journal of Personality and Social Psychology, 74 (3), 659-671.

Horn, J. \& Cattell, R. (1967). Age differences in fluid and crystallized intelligence. Acta Psychological, 26, 107-129.

King, A. (1998). Transactive peer tutoring: distributing cognition and metacognition. Educational Psychology 10, 57-74.

Landis, J., \& Koch, G. (1977). The measure of observable agreement for categorical data. Biometrics, 33, 159-174.

Leary, M., Nezlek, J., Downs, D., Radford-Davenport, J., Martin, J., \& McMullen, A. (1994). Self-presentation in every day interactions effects of target familiarity and gender composition. Journal of personality and social psychology 67, $664-673$. 
Margrett, J. (1999). Collaborative cognition and aging: A pilot study. Unpublished doctoral dissertation, Wayne State University.

Margrett, J. \& Marsiske, M. (2002). Gender differences in older adults’ everyday cognitive collaboration. International Journal of Behavioral Development, 26, $45-59$.

McArdle, J., Hamagami, F., Merideth, W., \& Bradway, K. (2000). Modeling the dynamic hypothesis of Gf - Gc theory using longitudinal life-span data. Learning \& Individual Differences 12, 53-80.

McNaughton, S. \& Leyland, J. (1999). The shifting focus of maternal tutoring across different difficulty levels on a problem-solving task. In P. Lloyd (Ed.) \& C. Fenyhough (Ed.), Lev Vygotsky: Critical assessments (pp. 132-142). New York: Routledge.

Meegan, S. \& Berg, C. (2002). Contexts, functions, forms, and processes of collaborative everyday problem solving in older adulthood. International Journal of Behavioral Development, 26, 6-15.

Meins, E. (1999). Security of attachment and maternal tutoring strategies: Interaction within the zone of proximal development. In P. Lloyd (Ed.) \& C. Fenyhough (Ed.), Lev Vygotsky: Critical assessments (pp. 113-131). New York: Routledge.

Noller, P., Feeney, J., Bonnell, D., \& Callan, V. (1994). A longitudinal study of conflict in early marriage. Journal of Social and Personal Relationships 11, 233-252. 
Pratt, M. W., Kerig, P., Cowan, P. A., \& Cowan, C. P. (1999). Mothers and fathers teaching 3-year-olds: Authorative parenting and adult scaffolding of young children’s learning. In P. Lloyd (Ed.) \& C. Fenyhough (Ed.), Lev Vygotsky: Critical assessments (pp. 143-162). New York: Routledge.

Reinharz, S. (1994). Qualitative evaluation policy. In J. F. Gubrium \& A. Sankar (eds.), Qualitative methods in aging research (pp. 266-273). Thousand Oaks, CA: Sage.

Radziszewska, B., \& Rogoff, B. (1988). Influence of adult and peer collaborators on children’s planning skills. Developmental Psychology, 24, 840-848.

Sagie, A. (1996). Effects of leaders' communication style and participative goal setting on performance and attitudes. Human Performance, 9, 51 - 64.

Salthouse, T. (1993). Speed and knowledge as determinants of old age differences in verbal tasks. Journals of Gerontology, 27, 29-36.

Salthouse, T. (1991). Cognitive facets of aging well. Generations, 15, 35-38.

Samaha, N. \& De Lisi, R. (2000). Peer collaborations on a nonverbal reasoning task by urban, minority students. Journal of Experimental Education, 69, 5-22.

Schaie, K. W. (1996). The course of adult intellectual development, American Psychologist, 49, 304-313.

Staudinger, U. M. \& Baltes, P. B (1996). Interactive minds: A facilitative setting for wisdom-related performance? Journal of Personality and Social Psychology, 71 (4), 746-762.

Stevens, J. (1996). Applied Multivariate Statistics for the Social Sciences. Mahwah, NJ: Lawrence Erlbaum. 
Strough, J., Berg, C. A., \& Meegan, S. P. (2001). Friendship and gender differences in task and social interpretations of peer collaborative problem solving. Social Development, 10, 1-22.

Strough, J. \& Margrett, J. (2002). Overview of the special section on collaborative cognition in later adulthood. International Journal of Behavioral Development, 26, $1-6$.

Strough, J., Swenson, L. M., \& Cheng, S. (2001). Friendship, gender, and preadolescents’ representations of peer collaboration. Merrill-Palmer Quarterly, 47, 475-499.

Thurstone, T. G. (1962). Primary mental ability for grades 9-12, (Rev. Ed.). Chicago, IL: Science Research Associates.

Tudge, J. \& Rogoff, B. (1999). Peer influences on cognitive development: Piagetian and Vygotskian perspectives. In P. Lloyd (Ed.) \& C. Fenyhough (Ed.), Lev Vygotsky: Critical assessments (pp. 32-56). New York: Routledge.

Tuites, A. \& Tuites, D. (1986). Equality in male/female relationships. Individual Psychology: Journal of Adlerian Theory, Research and Practice 42, 191-200.

U.S. Census (2001). Retrieved April, 2002, from U.S. Census: http://www.census.gov/prod/1/pop/p23-190/p23190-g.pdf.

Vygotsky, L. S. (1994). Thought and Language. (A. Kozulin, Trans.). Massachusetts: The MIT Press. (Origonal work published in 1934).

Wallace, K., Martin, M., McMillan, S., \& Mell, M. (1999). When strangers disagree: expressive response styles and attitude change. Journal of Social Behavior and Personality 14, 197-207. 
Wertsch, J. V. (1999). The zone of proximal development: Some conceptual issues. In P. Lloyd (Ed.) \& C. Fenyhough (Ed.), Lev Vygotsky: Critical assessments (pp. 67-80). New York: Routledge.

Williams, P. (2001). Children’s ways of experiencing peer interaction. Early Child Development and Care 16, 17-38.

Willis, S. L., \& Marsiske, M. (1993). Manual for the Everyday Problems Test. University Park, PA: Department of Human Development and Family Studies, The Pennsylvania State University. 


\section{Table 1}

Summary of Analysis of Variance Comparing Subsample Characteristics to Full Sample Characteristics.

\begin{tabular}{llcc}
\hline Sample & Demographics & $F$ & $p$ \\
\hline $\begin{array}{l}\text { Subsample }(N=80) \\
\text { Full Sample }(N=196)\end{array}$ & Age & .80 & .37 \\
$\begin{array}{l}\text { Subsample }(N=80) \\
\text { Full Sample }(N=196)\end{array}$ & Education & .00 & .99 \\
$\begin{array}{l}\text { Subsample }(N=78) \\
\text { Full Sample }(N=186)\end{array}$ & Income & .45 & .50 \\
$\begin{array}{l}\text { Subsample }(N=80) \\
\text { Full Sample }(N=196)\end{array}$ & Marriage Length & & \\
\hline
\end{tabular}


Table 2

Descriptive Statistics for Personality Variables, Cognitive Ability, and Collaborative Outcome ( $N=80$ individuals).

Range $\quad$ Mean $\quad S D$

Personality

Openness

$2.17-4.00$

3.25

0.42

Extroversion

$1.92-4.33$

3.47

0.48

Problem Solving

$\begin{array}{lccr}\text { EPT Individual Performance } & 30.00-62.00 & 50.44 & 9.40 \\ \text { EPT Collaborative Performance } & 30.00-62.00 & 51.76 & 7.49 \\ \text { EPT Difference Score } & -16.30-22.58 & 1.32 & 8.38 \\ \text { pectations } & 11.00-25.00 & 18.48 & 2.70\end{array}$

Cognitive Ability

G Score

$3.33-22.33$

14.72

4.40

Note. G score is a composite score composed of three measures of cognitive ability (Verbal Meaning Test, Number Comparison Test, and Letter Series Test). EPT = Everyday Problems Test. 
Table 3

Total Frequencies and Proportions of Behaviors Exhibited Throughout the Everyday Problems Test ( $N=80$ individuals)

\begin{tabular}{|c|c|c|c|c|}
\hline Behavior & Range & Mean & $S D$ & Total Sample \\
\hline \multicolumn{5}{|l|}{ Demands } \\
\hline Frequency & $0-.49$ & 3.79 & 6.34 & 303.00 \\
\hline Proportion & $0-.21$ & .03 & .03 & .03 \\
\hline \multicolumn{5}{|l|}{ Tutoring } \\
\hline Frequency & $7-115$ & 53.56 & 25.52 & 4285.00 \\
\hline Proportion & $.16-.64$ & .41 & .10 & .42 \\
\hline \multicolumn{5}{|c|}{ Task Irrelevance } \\
\hline Frequency & $0-98$ & 15.10 & 18.43 & 1208.00 \\
\hline Proportion & $0-.43$ & .11 & .10 & .12 \\
\hline \multicolumn{5}{|l|}{ Encouragement } \\
\hline Frequency & $0-60$ & 28.15 & 14.66 & 2252.00 \\
\hline Proportion & $0-.47$ & .22 & .09 & .22 \\
\hline \multicolumn{5}{|l|}{ Reads Question } \\
\hline Frequency & $0-34$ & 10.04 & 8.00 & 803.00 \\
\hline Proportion & $0-.24$ & .08 & .05 & .08 \\
\hline \multicolumn{5}{|c|}{ Answers Question } \\
\hline Frequency & $1-28$ & 11.25 & 5.93 & 900.00 \\
\hline Proportion & $.01-.25$ & .10 & .06 & .09 \\
\hline \multicolumn{5}{|l|}{ Other } \\
\hline Frequency & $0-20$ & 6.30 & 4.75 & 504.00 \\
\hline Proportion & $0-.24$ & .05 & .04 & .01 \\
\hline $\begin{array}{l}\text { Total Task } \\
\text { Behaviors }\end{array}$ & $17-249$ & 128.14 & 49.97 & 10251.00 \\
\hline
\end{tabular}


Table 4

Bivariate Correlations Between Self Behaviors and Partner Behaviors ( $N=40$ dyads)

\begin{tabular}{|c|c|c|c|c|c|c|c|}
\hline & $\begin{array}{c}\text { Male } \\
\text { Tutoring }\end{array}$ & $\begin{array}{c}\text { Male } \\
\text { Task Irr. }\end{array}$ & $\begin{array}{l}\text { Male } \\
\text { Enc. }\end{array}$ & $\begin{array}{c}\text { Female } \\
\text { Dem. }\end{array}$ & $\begin{array}{c}\text { Female } \\
\text { Tutoring }\end{array}$ & $\begin{array}{c}\text { Female } \\
\text { Task Irr. }\end{array}$ & $\begin{array}{c}\text { Female } \\
\text { Enc. }\end{array}$ \\
\hline Male Dem. & -.22 & -.21 & -.10 & .10 & .15 & -.06 & -.06 \\
\hline Male Tutoring & & $-.42 * *$ & $-.57 * *$ & .16 & .05 & -.20 & .19 \\
\hline Male Task Irr. & & & -.03 & -.28 & -.31 & $.65 * *$ & -.06 \\
\hline Male Enc. & & & & -.21 & .12 & -.12 & -.06 \\
\hline Female Dem. & & & & & -.03 & -.20 & -.08 \\
\hline Female Tutoring & & & & & & $-.53 * *$ & $-.65^{* *}$ \\
\hline Female Task Irr & & & & & & & -.01 \\
\hline
\end{tabular}

Note. Correlations represent the relationship between the proportion of behaviors exhibited by the individual (self) and his or her partner. Dem. = Demands, Task Irr. = Task Irrelevance, and Enc. = Encouragement.

${ }^{*} p<.05 .{ }^{* *} p<.01$. 
Table 5

Analysis of Variance for Demands ( $N=80$ individuals).

\begin{tabular}{lccc}
\hline Source & $d f$ & $F$ & $p$ \\
\hline Participant Sex (S) & 1 & 0.25 & .62 \\
Performance Order (O) & 1 & 0.40 & .53 \\
Partner Familiarity (F) & 1 & $3.96^{*}$ & .05 \\
$\mathrm{~S} * \mathrm{O}$ & 1 & 0.10 & .76 \\
$\mathrm{~S} * \mathrm{~F}$ & 1 & 2.04 & .16 \\
$\mathrm{O} * \mathrm{~F}$ & 1 & 0.89 & .35 \\
$\mathrm{~S} \mathrm{O}^{*} \mathrm{~F}$ & 1 & 0.11 & .75 \\
Error & 72 & &
\end{tabular}

Note. Performance Order indicates whether an individual performed the Everyday Problems Test alone first or with a partner first. Partner Familiarity refers to whether an individual worked with their spouse or a stranger when completing the Everyday Problems Test collaboratively. $* p<.05$. 
Table 6

Analysis of Variance for Tutoring ( $N=80$ individuals).

\begin{tabular}{lccc}
\hline Source & $d f$ & $F$ & $p$ \\
\hline Participant Sex (S) & 1 & 1.82 & .18 \\
Performance Order (O) & 1 & 0.02 & .89 \\
Partner Familiarity (F) & 1 & 1.61 & .21 \\
S*O & 1 & 2.47 & .12 \\
S*F & 1 & 0.85 & .36 \\
O*F & 1 & 0.04 & .84 \\
S*O*F & 1 & 0.01 & .94 \\
Error & 72 & &
\end{tabular}

Note. Performance Order indicates whether an individual performed the Everyday Problems Test alone first or with a partner first. Partner Familiarity refers to whether an individual worked with their spouse or a stranger when completing the Everyday Problems Test collaboratively. 
Table 7

Analysis of Variance for Task Irrelevance ( $N=80$ individuals).

\begin{tabular}{lccc}
\hline Source & $d f$ & $F$ & $p$ \\
\hline Participant Sex (S) & 1 & 3.42 & .07 \\
Performance Order (O) & 1 & $17.41^{* *}$ & .01 \\
Partner Familiarity (F) & 1 & $8.94^{* *}$ & .01 \\
S*O & 1 & 1.99 & .16 \\
$\mathrm{~S}^{*} \mathrm{~F}$ & 1 & 1.68 & .20 \\
$\mathrm{O} * \mathrm{~F}$ & 1 & 1.52 & .22 \\
$\mathrm{~S} * \mathrm{O} * \mathrm{~F}$ & 1 & 0.11 & .74 \\
Error & 72 & &
\end{tabular}

Note. Performance Order indicates whether an individual performed the Everyday Problems Test alone first or with a partner first. Partner Familiarity refers to whether an individual worked with their spouse or a stranger when completing the Everyday Problems Test collaboratively. $* * p<.01$. 
Table 8

\begin{tabular}{lccc} 
Analysis of Variance for Encouragement $(N=80$ & individuals $)$ \\
\hline Source & $d f$ & $F$ & $p$ \\
\hline Participant sex (S) & 1 & 1.57 & .22 \\
Performance Order (O) & 1 & 0.67 & .42 \\
Partner Familiarity (F) & 1 & 0.06 & .81 \\
S*O & 1 & 2.10 & .15 \\
S*F & 1 & 0.17 & .68 \\
O*F & 1 & 0.79 & .38 \\
S*O*F & 1 & 0.24 & .62 \\
Error & 72 & &
\end{tabular}

Note. Performance Order indicates whether an individual performed the Everyday Problems Test alone first or with a partner first. Partner Familiarity refers to whether an individual worked with their spouse or a stranger when completing the Everyday Problems Test collaboratively. 
Table 9

Summary of Hierarchical Regression Analysis Predicting Demands ( $N=80$ individuals).

Predictors $\beta$

$R^{2} \quad \Delta R^{2} \quad F$

Step

Full Model

Step 1

Performance order

$-.10$

Familiarity

$.22 *$

.21

Step 2

.08

$.03 \quad 0.90$

Participant sex

.08

.08

EPT expectations

.04

.07

Extroversion

$-.13$

$-.13$

Openness

.08

.09

G score

$-.12$

Step 3

Partner's EPT expectations

Partner's extroversion

.01

.01

Partner's openness

Partner’s G score

.12

.12

Note. G score is a composite score composed of three measures of cognitive ability (Verbal Meaning Test, Number Comparison Test, and Letter Series Test). EPT = Everyday Problems Test. Performance Order indicates whether an individual performed the Everyday Problems Test alone first or with a partner first. Partner Familiarity refers to whether an individual worked with their spouse or a stranger when completing the Everyday Problems Test collaboratively.

$* p<.05$. 
Table 10

Summary of Hierarchical Regression Analysis Predicting Tutoring ( $N=80$ individuals).

\begin{tabular}{|c|c|c|c|c|c|}
\hline \multirow[t]{2}{*}{ Predictors } & \multicolumn{2}{|c|}{$\beta$} & \multirow[t]{2}{*}{$R^{2}$} & \multirow[t]{2}{*}{$\Delta R^{2}$} & \multirow[t]{2}{*}{$F$} \\
\hline & Step & Full Model & & & \\
\hline Step 1 & & & .02 & & 0.81 \\
\hline Performance order & .02 & .09 & & & \\
\hline Familiarity & .14 & .13 & & & \\
\hline Step 2 & & & .08 & .06 & 0.92 \\
\hline Participant sex & -.18 & -.16 & & & \\
\hline EPT expectations & .13 & .08 & & & \\
\hline Extroversion & .11 & .15 & & & \\
\hline Openness & .00 & .06 & & & \\
\hline G score & .09 & .22 & & & \\
\hline Step 3 & & & $.25 *$ & $.17 * *$ & $3.04 *$ \\
\hline Partner's EPT expectations & .02 & .02 & & & \\
\hline Partner's extroversion & .03 & .03 & & & \\
\hline Partner's openness & -.10 & -.10 & & & \\
\hline Partner's G score & $-.43 * *$ & $-.43 * *$ & & & \\
\hline
\end{tabular}

Note. G score is a composite score composed of three measures of cognitive ability (Verbal Meaning Test, Number Comparison Test, and Letter Series Test). EPT = Everyday Problems Test. Performance Order indicates whether an individual performed the Everyday Problems Test alone first or with a partner first. Partner Familiarity refers to whether an individual worked with their spouse or a stranger when completing the Everyday Problems Test collaboratively.

$* p<.05 . * * p<.01$. 


\section{Table 11}

Summary of Hierarchical Regression Analysis Predicting Task Irrelevance $(N=80$ individuals).

\begin{tabular}{|c|c|c|c|c|c|}
\hline \multirow[t]{2}{*}{ Predictors } & \multicolumn{2}{|c|}{$\beta$} & \multirow[t]{2}{*}{$R^{2}$} & \multirow[t]{2}{*}{$\Delta R^{2}$} & \multirow[t]{2}{*}{$F$} \\
\hline & Step & Full Model & & & \\
\hline Step 1 & & & $.25 * *$ & & $12.75 * *$ \\
\hline Performance order & $.40 * *$ & $.34 * *$ & & & \\
\hline Familiarity & $-.29 * *$ & $-.31 * *$ & & & \\
\hline Step 2 & & & $.31 * *$ & .07 & $4.41 * *$ \\
\hline Participant sex & $.22 *$ & .19 & & & \\
\hline EPT expectations & -.02 & -.01 & & & \\
\hline Extroversion & -.16 & -.18 & & & \\
\hline Openness & .15 & .15 & & & \\
\hline G score & .00 & -.02 & & & \\
\hline Step 3 & & & $.34 * *$ & .03 & $3.24 * *$ \\
\hline Partner's EPT expectations & .03 & .03 & & & \\
\hline Partner's extroversion & -.14 & -.14 & & & \\
\hline Partner's openness & .00 & .00 & & & \\
\hline Partner's G score & .09 & .09 & & & \\
\hline
\end{tabular}

Note. G score is a composite score composed of three measures of cognitive ability (Verbal Meaning Test, Number Comparison Test, and Letter Series Test). EPT = Everyday Problems Test. Performance Order indicates whether an individual performed the Everyday Problems Test alone first or with a partner first. Partner Familiarity refers to whether an individual worked with their spouse or a stranger when completing the Everyday Problems Test collaboratively.

$* * p<.01$. 
Table 12

Summary of Hierarchical Regression Analysis Predicting Encouragement $(N=80$ individuals).

\begin{tabular}{|c|c|c|c|c|c|}
\hline \multirow[t]{2}{*}{ Predictors } & \multicolumn{2}{|c|}{$\beta$} & \multirow[t]{2}{*}{$R^{2}$} & \multirow[t]{2}{*}{$\Delta R^{2}$} & \multirow[t]{2}{*}{$F$} \\
\hline & Step & Full Model & & & \\
\hline Step 1 & & & .01 & & 0.37 \\
\hline Performance order & -.09 & -.13 & & & \\
\hline Familiarity & -.03 & -.01 & & & \\
\hline Step 2 & & & .09 & .08 & 0.99 \\
\hline Participant sex & .14 & .13 & & & \\
\hline EPT expectations & -.14 & -.08 & & & \\
\hline Extroversion & .02 & -.01 & & & \\
\hline Openness & -.11 & -.21 & & & \\
\hline G score & -.11 & -.22 & & & \\
\hline Step 3 & & & $.26^{*}$ & $.17^{* *}$ & $2.12^{*}$ \\
\hline Partner's EPT expectations & .07 & .07 & & & \\
\hline Partner's extroversion & .04 & .04 & & & \\
\hline Partner's openness & .16 & .16 & & & \\
\hline Partner’s G score & $.37 * *$ & $.37 * *$ & & & \\
\hline
\end{tabular}

Note. G score is a composite score composed of three measures of cognitive ability (Verbal Meaning Test, Number Comparison Test, and Letter Series Test). EPT = Everyday Problems Test. Performance Order indicates whether an individual performed the Everyday Problems Test alone first or with a partner first. Partner Familiarity refers to whether an individual worked with their spouse or a stranger when completing the Everyday Problems Test collaboratively.

$* p<.05$. ** $p<.01$. 
Table 13

Summary of Hierarchical Regression Analysis Predicting Everyday Problem Solving Performance Difference Score ( $N=80$ individuals).

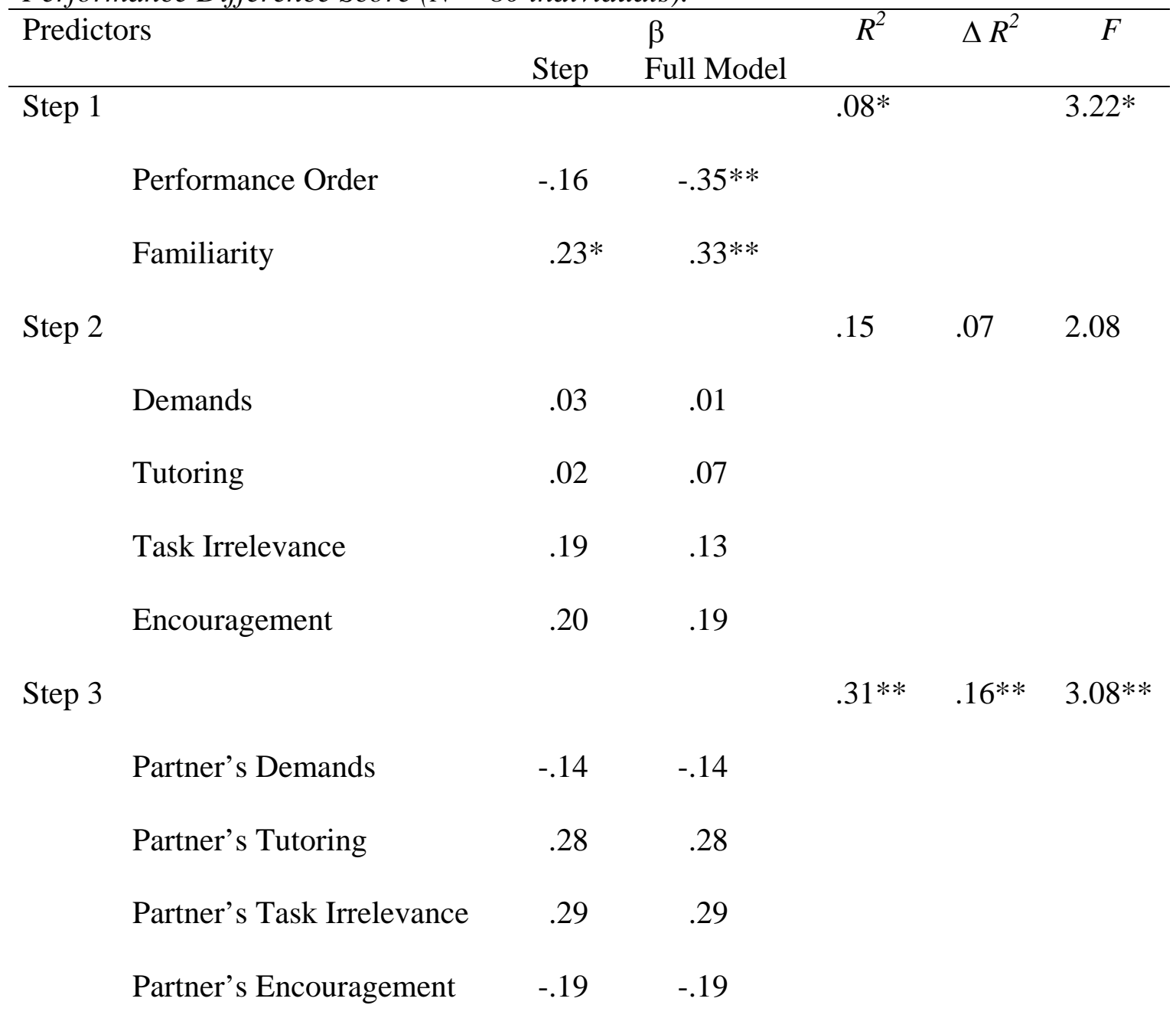

Note. Difference score $=$ the difference between an individuals' score when performing the EPT alone and when performing the EPT collaboratively. EPT = Everyday Problems Test. Performance Order indicates whether an individual performed the Everyday Problems Test alone first or with a partner first. Partner Familiarity refers to whether an individual worked with their spouse or a stranger when completing the Everyday Problems Test collaboratively. $* p<.05 . * * p<.01$. 
Table 14

Proportion of Interactive Behaviors Overall and During Beginning, Middle, and End Session Segments $(N=80$ individuals).

\begin{tabular}{|c|c|c|c|c|c|c|c|c|}
\hline \multirow{3}{*}{ Behavior } & \multicolumn{4}{|c|}{ Familiar Dyads } & \multicolumn{4}{|c|}{ Unfamiliar Dyads } \\
\hline & \multirow{2}{*}{\multicolumn{2}{|c|}{$\begin{array}{c}\text { Individual } \\
\text { First }\end{array}$}} & \multirow{2}{*}{\multicolumn{2}{|c|}{$\begin{array}{c}\text { Collaborative } \\
\text { First }\end{array}$}} & \multirow{2}{*}{\multicolumn{2}{|c|}{$\begin{array}{l}\text { Individual } \\
\text { First }\end{array}$}} & \multirow{2}{*}{\multicolumn{2}{|c|}{$\begin{array}{c}\text { Collaborative } \\
\text { First }\end{array}$}} \\
\hline & & & & & & & & \\
\hline Demands & Male & Female & Male & Female & Male & Female & Male & Female \\
\hline Beginning & .03 & .03 & .04 & .04 & .00 & .03 & .02 & .01 \\
\hline Middle & .01 & .02 & .03 & .05 & .02 & .02 & .01 & .01 \\
\hline End & .03 & .06 & .02 & .04 & .05 & .01 & .02 & .01 \\
\hline Total & .02 & .04 & .03 & .05 & .02 & .02 & .02 & .01 \\
\hline \multicolumn{9}{|l|}{ Tutoring } \\
\hline Beginning & .03 & .35 & .41 & .34 & .29 & .36 & .37 & .33 \\
\hline Middle & .05 & .44 & .46 & .41 & .45 & .41 & .41 & .37 \\
\hline End & .05 & .41 & .52 & .41 & .34 & .38 & .50 & .36 \\
\hline Total & .04 & .40 & .46 & .39 & .36 & .38 & .43 & .35 \\
\hline \multicolumn{9}{|l|}{ Task Irrelevance } \\
\hline Beginning & .03 & .02 & .09 & .15 & .09 & .07 & .16 & .12 \\
\hline Middle & .03 & .07 & .03 & .06 & .08 & .11 & .17 & .23 \\
\hline End & .05 & .09 & .07 & .16 & .08 & .07 & .13 & .18 \\
\hline Total & .04 & .06 & .06 & .09 & .08 & .08 & .15 & .18 \\
\hline \multicolumn{9}{|l|}{ Encouragement } \\
\hline Beginning & .24 & .28 & .14 & .24 & .28 & .24 & .23 & .28 \\
\hline Middle & .25 & .21 & .18 & .27 & .19 & .14 & .22 & .23 \\
\hline End & .24 & .22 & .17 & .25 & .23 & .23 & .19 & .23 \\
\hline Total & .24 & .24 & .16 & .25 & .23 & .20 & .22 & .25 \\
\hline
\end{tabular}




\section{Table 15}

Analysis of Variance Assessing Group Differences in Demands at Beginning Middle and End Session Segments ( $N=80$ individuals).

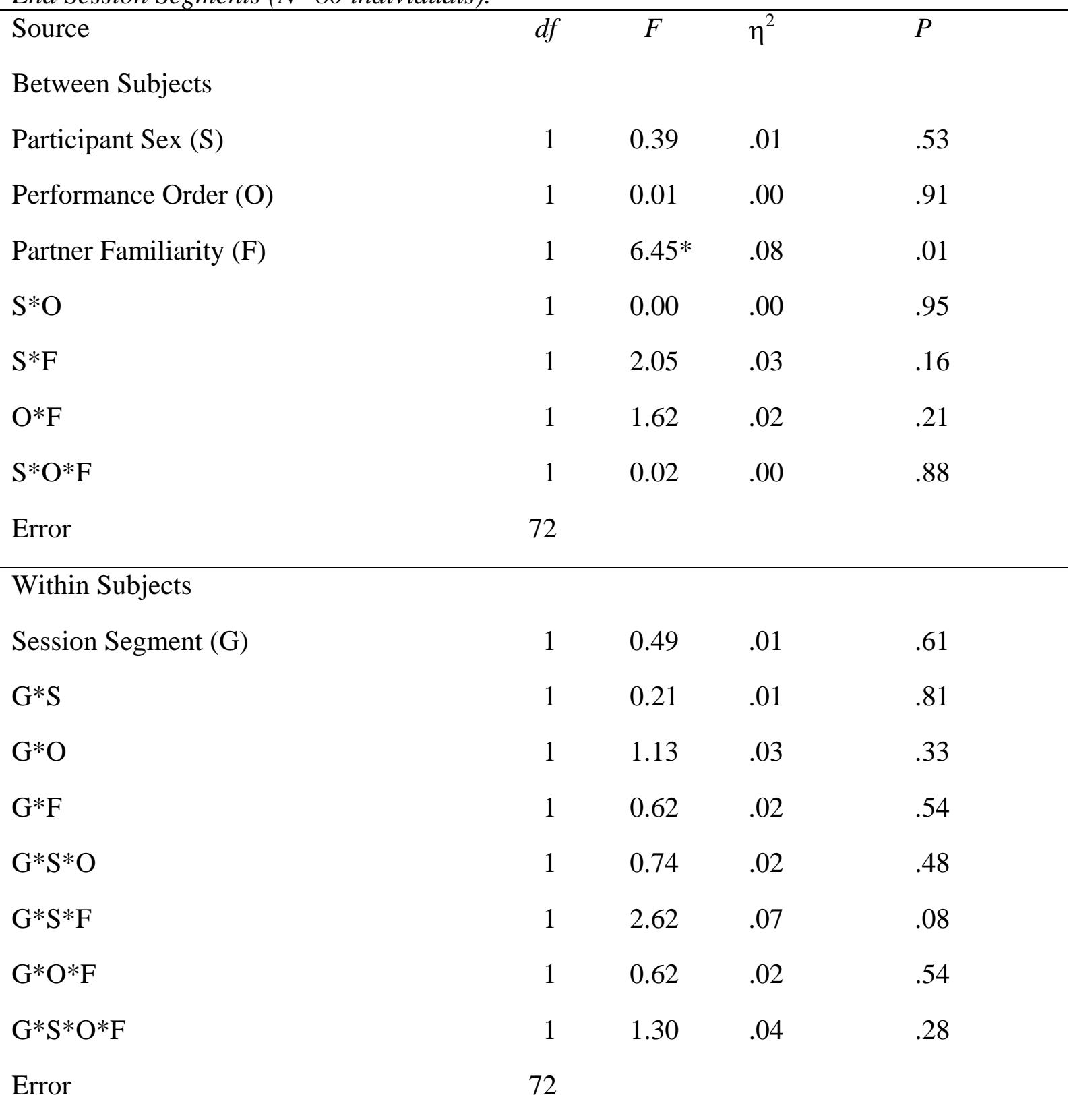

Note. Performance Order indicates whether an individual performed the Everyday Problems Test alone first or with a partner first. Partner Familiarity refers to whether an individual worked with their spouse or a stranger when completing the Everyday Problems Test collaboratively.

$* p<.05$. 


\section{Table 16}

Analysis of Variance Assessing Group Differences in Tutoring at Beginning Middle and End Session Segments ( $N=80$ individuals).

\begin{tabular}{|c|c|c|c|c|}
\hline Source & $d f$ & $F$ & $\eta^{2}$ & $p$ \\
\hline \multicolumn{5}{|l|}{ Between Subjects } \\
\hline Participant Sex (S) & 1 & 2.00 & .03 & .16 \\
\hline Performance Order (O) & 1 & 0.72 & .01 & .40 \\
\hline Partner Familiarity (F) & 1 & 2.23 & .03 & .14 \\
\hline $\mathrm{S} * \mathrm{O}$ & 1 & 2.85 & .04 & .10 \\
\hline $\mathrm{S} * \mathrm{~F}$ & 1 & 0.16 & .00 & .69 \\
\hline $\mathrm{O} * \mathrm{~F}$ & 1 & 0.00 & .00 & .97 \\
\hline $\mathrm{S} * \mathrm{O} * \mathrm{~F}$ & 1 & 0.11 & .00 & .74 \\
\hline Error & 72 & & & \\
\hline \multicolumn{5}{|l|}{ Within Subjects } \\
\hline Session Segment (G) & 1 & $9.70 * *$ & .21 & .01 \\
\hline $\mathrm{G} * \mathrm{~S}$ & 1 & 1.09 & .03 & .34 \\
\hline $\mathrm{G}^{*} \mathrm{O}$ & 1 & 2.07 & .05 & .13 \\
\hline $\mathrm{G}^{*} \mathrm{~F}$ & 1 & 0.38 & .01 & .68 \\
\hline $\mathrm{G} * \mathrm{~S} * \mathrm{O}$ & 1 & 1.18 & .03 & .31 \\
\hline $\mathrm{G}^{*} \mathrm{~S} * \mathrm{~F}$ & 1 & 0.14 & .00 & .87 \\
\hline $\mathrm{G} * \mathrm{O} * \mathrm{~F}$ & 1 & 0.31 & .01 & .73 \\
\hline $\mathrm{G}^{*} \mathrm{~S} * \mathrm{O} * \mathrm{~F}$ & 1 & 0.45 & .01 & .64 \\
\hline Error & 72 & & & \\
\hline
\end{tabular}

Note. Performance Order indicates whether an individual performed the Everyday Problems Test alone first or with a partner first. Partner Familiarity refers to whether an individual worked with their spouse or a stranger when completing the Everyday Problems Test collaboratively.

$* * p<.01$. 
Table 17

Analysis of Variance Assessing Group Differences in Task Irrelevance at Beginning Middle and End Session Segments ( $N=80$ individuals).

\begin{tabular}{|c|c|c|c|c|}
\hline Source & $d f$ & $F$ & $\eta^{2}$ & $p$ \\
\hline \multicolumn{5}{|l|}{ Between Subjects } \\
\hline Participant Sex (S) & 1 & $4.01 *$ & .05 & .05 \\
\hline Performance Order (O) & 1 & $15.95 * *$ & .19 & .01 \\
\hline Partner Familiarity (F) & 1 & $13.34 * *$ & .15 & .01 \\
\hline $\mathrm{S} * \mathrm{O}$ & 1 & 0.89 & .01 & .35 \\
\hline $\mathrm{S}^{*} \mathrm{~F}$ & 1 & 0.41 & .01 & .53 \\
\hline $\mathrm{O} * \mathrm{~F}$ & 1 & 1.29 & .02 & .26 \\
\hline $\mathrm{S} * \mathrm{O} * \mathrm{~F}$ & 1 & 0.06 & .00 & .80 \\
\hline Error & 72 & & & \\
\hline \multicolumn{5}{|l|}{ Within Subjects } \\
\hline Session Segment (G) & 1 & 0.11 & .00 & .89 \\
\hline $\mathrm{G} * \mathrm{~S}$ & 1 & 1.15 & .03 & .32 \\
\hline $\mathrm{G}^{*} \mathrm{O}$ & 1 & 1.35 & .04 & .27 \\
\hline $\mathrm{G}^{*} \mathrm{~F}$ & 1 & $3.57 *$ & .09 & .03 \\
\hline $\mathrm{G} * \mathrm{~S} * \mathrm{O}$ & 1 & 0.41 & .01 & .67 \\
\hline $\mathrm{G}^{*} \mathrm{~S} * \mathrm{~F}$ & 1 & 0.67 & .02 & .51 \\
\hline $\mathrm{G}^{*} \mathrm{O} * \mathrm{~F}$ & 1 & 2.12 & .06 & .13 \\
\hline $\mathrm{G}^{*} \mathrm{~S}^{*} \mathrm{O} * \mathrm{~F}$ & 1 & 0.16 & .00 & .85 \\
\hline Error & 72 & & & \\
\hline
\end{tabular}

Note. Performance Order indicates whether an individual performed the Everyday Problems Test alone first or with a partner first. Partner Familiarity refers to whether an individual worked with their spouse or a stranger when completing the Everyday Problems Test collaboratively.

${ }^{*} p<.05 .{ }^{* *} p<.01$. 
Table 18

Analysis of Variance Assessing Group Differences in Encouragement at Beginning Middle and End Session Segments ( $N=80$ individuals).

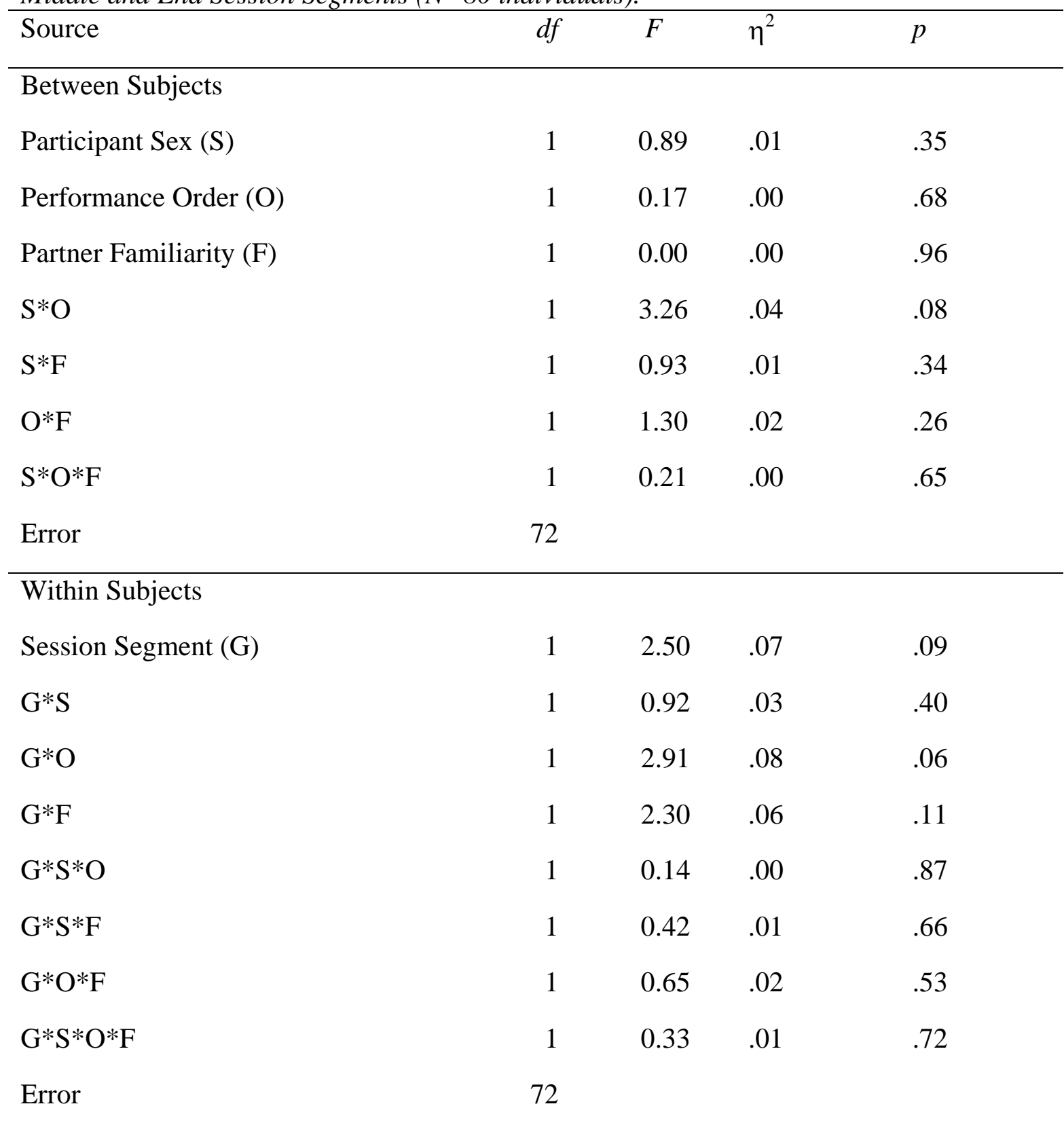

Note. Performance Order indicates whether an individual performed the Everyday Problems Test alone first or with a partner first. Partner Familiarity refers to whether an individual worked with their spouse or a stranger when completing the Everyday Problems Test collaboratively. ${ }^{*} p<.05 .{ }^{* *} p<.01$. 
Table 19

Summary of Separate Hierarchical Regressions Predicting Demands During the Beginning, Middle, and End Session Segments ( $N=80$ individuals).

\begin{tabular}{|c|c|c|c|c|}
\hline $\begin{array}{l}\text { Session } \\
\text { Segment }\end{array}$ & Step & $R^{2}$ & $\Delta R^{2}$ & $F$ \\
\hline \multirow[t]{3}{*}{ Beginning } & 1 & $.11^{*}$ & & $4.89 * *$ \\
\hline & 2 & .12 & .01 & 1.43 \\
\hline & 3 & .17 & .05 & 1.24 \\
\hline \multirow[t]{3}{*}{ Middle } & 1 & .03 & & 1.23 \\
\hline & 2 & .07 & .04 & 0.76 \\
\hline & 3 & .09 & .02 & 0.63 \\
\hline \multirow[t]{3}{*}{ End } & 1 & .03 & & 1.10 \\
\hline & 2 & .07 & .04 & 0.73 \\
\hline & 3 & .11 & .05 & 0.80 \\
\hline \multicolumn{5}{|c|}{$\begin{array}{l}\text { Note. Step } 1 \text { = Design Characteristics (performance order and partner familiarity), Step } \\
2 \text { = Individual Characteristics (sex, cognitive ability, personality, and expectations), Step } \\
3=\text { Partner Characteristics (cognitive ability, personality, and expectations). } \\
* * p<.01 .\end{array}$} \\
\hline
\end{tabular}


Table 20

Summary of Separate Hierarchical Regressions Predicting Tutoring During the Beginning, Middle, and End Session Segments ( $N=80$ individuals).

\begin{tabular}{llccc}
\hline $\begin{array}{l}\text { Session } \\
\text { Segment }\end{array}$ & Step & $R^{2}$ & $\Delta R^{2}$ & $F$ \\
\hline Beginning & 1 & .02 & .04 & 0.73 \\
& 2 & .05 & $.13^{*}$ & 1.36 \\
Middle & 3 & .18 & .59 & 0.91 \\
& 1 & .02 & .04 & 0.74 \\
& 2 & .07 & .10 & 1.27 \\
End & 3 & .17 & & 2.06 \\
& 1 & .05 & .08 & 1.50 \\
& 2 & .13 & .11 & 1.89 \\
\hline
\end{tabular}

Note. Step 1 = Design Characteristics (performance order and partner familiarity), Step 2 = Individual Characteristics (sex, cognitive ability, personality, and expectations), Step

$3=$ Partner Characteristics (cognitive ability, personality, and expectations).

$* p<.05$. 
Table 21

Summary of Separate Hierarchical Regressions Predicting Task Irrelevance During the Beginning, Middle, and End Session Segments ( $N=80$ individuals).

\begin{tabular}{|c|c|c|c|c|}
\hline $\begin{array}{l}\text { Session } \\
\text { Segment }\end{array}$ & Step & $R^{2}$ & $\Delta R^{2}$ & $F$ \\
\hline \multirow[t]{3}{*}{ Beginning } & 1 & $.21 * *$ & & $9.98 * *$ \\
\hline & 2 & $.22 * *$ & .02 & $2.94 * *$ \\
\hline & 3 & $.26^{*}$ & .03 & $2.11^{*}$ \\
\hline \multirow[t]{3}{*}{ Middle } & 1 & $.21 * *$ & & $10.12^{* *}$ \\
\hline & 2 & $.27 * *$ & .06 & $3.71 * *$ \\
\hline & 3 & $.31^{* *}$ & .04 & $2.76^{* *}$ \\
\hline \multirow[t]{3}{*}{ End } & 1 & $.08^{*}$ & & $3.34^{*}$ \\
\hline & 2 & .16 & .08 & 2.02 \\
\hline & 3 & .22 & .06 & 1.74 \\
\hline
\end{tabular}

Note. Step 1 = Design Characteristics (performance order and partner familiarity), Step 2 = Individual Characteristics (sex, cognitive ability, personality, and expectations), Step $3=$ Partner Characteristics (cognitive ability, personality, and expectations).

$* p<.05 . * * p<.01$. 
Table 22

Summary of Separate Hierarchical Regressions Predicting Encouragement During the Beginning, Middle, and End Session Segments ( $N=80$ individuals).

\begin{tabular}{lllll}
\hline $\begin{array}{l}\text { Session } \\
\text { Segment }\end{array}$ & Step & $R^{2}$ & $\Delta R^{2}$ & $F$ \\
\hline Beginning & 1 & .04 & .10 & 1.49 \\
& 2 & .14 & .09 & 1.63 \\
Middle & 3 & .23 & .04 & 1.85 \\
& 1 & .08 & .04 & 1.39 \\
& 2 & .18 & .10 & 0.88 \\
End & 3 & .01 & & 1.33 \\
& 1 & .04 & .03 & 0.18 \\
& 2 & .20 & $.16^{*}$ & 0.40
\end{tabular}

Note. Step 1 = Design Characteristics (performance order and partner familiarity), Step 2 = Individual Characteristics (sex, cognitive ability, personality, and expectations), Step $3=$ Partner Characteristics (cognitive ability, personality, and expectations).

$* p<.05$. 
Table 23

Summary of Hierarchical Regression Analysis Predicting Everyday Problem-solving Performance Difference Score by Session Segments ( $N=80$ individuals).

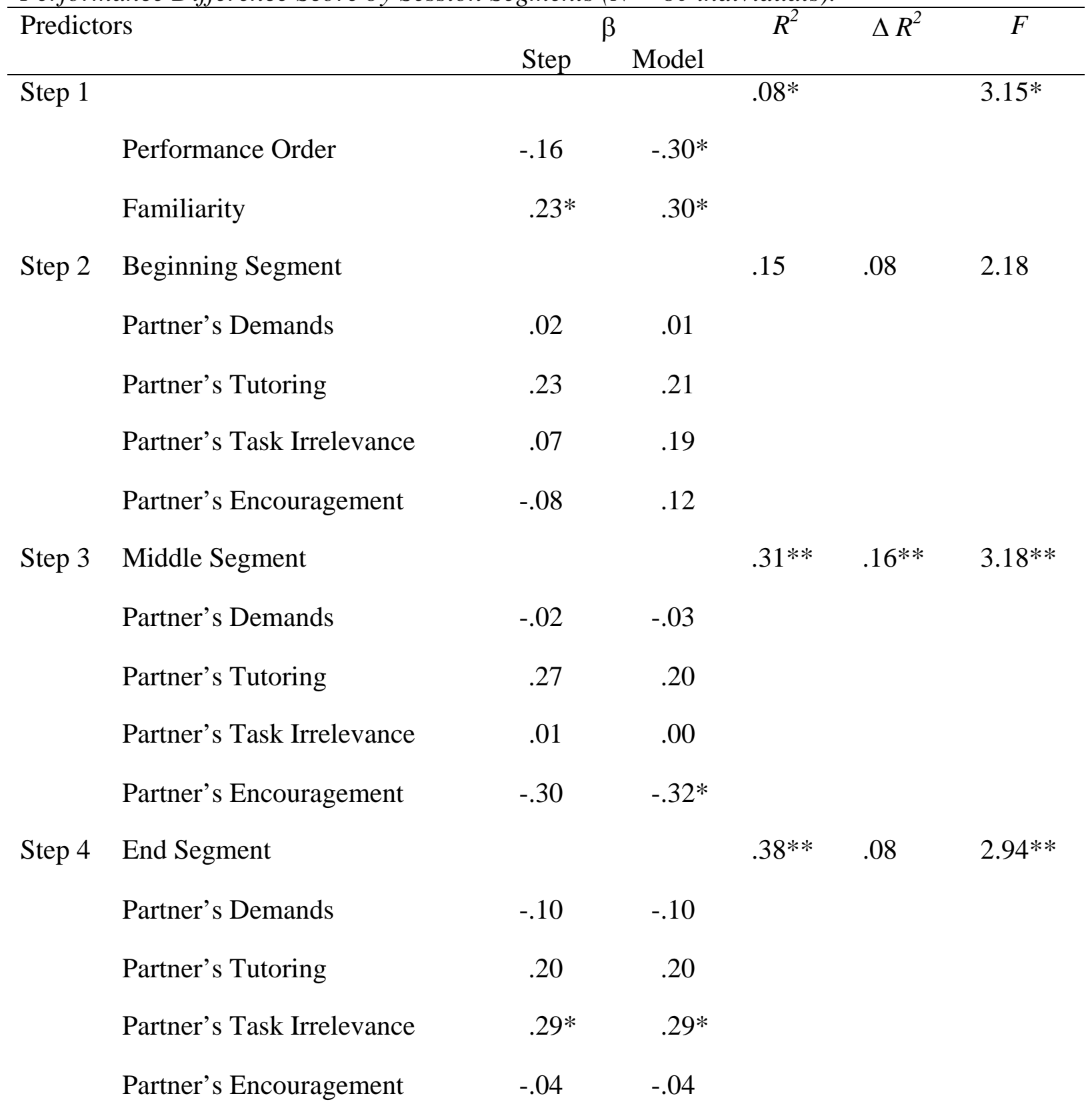

Note. Difference score is the difference between an individual's score when performing the Everyday Problems Test alone and when performing the Everyday Problems Test collaboratively. EPT = Everyday Problems Test. Performance Order indicates whether an individual performed the Everyday Problems Test alone first or with a partner first. Partner Familiarity refers to whether an individual worked with their spouse or a stranger when completing the Everyday Problems Test collaboratively. $* p<.05 . * * p<.01$. 
Table 24

Summary of Results.

Significant Findings $(p<.05)$

\begin{tabular}{lll}
\hline Research Question & Primary Analyses & Exploratory Analyses
\end{tabular}

RQ1: Group Differences

Demands

Tutoring

Task Irrelevance

Encouragement

RQ2: Predictors of

Interactive Behaviors

Demands

Tutoring

Task Irrelevance

Encouragement
Familiar partners displayed more demands than unfamiliar partners. There were no significant differences.

Individuals paired with an unfamiliar partner and individuals who performed the collaborative problem solving first displayed more task irrelevance.

There were no significant differences.

No steps were predictive.

The third step was predictive as partner's cognitive ability was a significant individual predictor.

Step one was a significant predictor as partner familiarity and performance order were both significant individual predictors. The third step was predictive as partner's cognitive ability was a significant individual predictor.
Segments provided no additional information.

There was a lower proportion of tutoring behaviors during the beginning of the task than the middle and end.

Segment by partner familiarity interaction suggested that individuals in the unfamiliar condition displayed more task irrelevance during the middle segment. There was a main effect for session segment. Segments provided no additional information.

Step one (performance order and partner familiarity) was a significant predictor for demands in the beginning segment.

None of the steps predicted tutoring in the middle segment.

Segments provided no additional information.

Segments provided no additional information. 
Table 24 (continued).

Significant Findings $(p<.05)$

\begin{tabular}{lll}
\hline Research Question & Primary Analyses & Exploratory Analyses \\
\hline $\begin{array}{l}\text { RQ3: Predictors of } \\
\text { Difference Score }\end{array}$ & $\begin{array}{l}\text { Step one and step three were } \\
\text { significant predictors as } \\
\text { partner familiarity was a } \\
\text { significant individual } \\
\text { predictor. }\end{array}$ & $\begin{array}{l}\text { Partner behaviors during the } \\
\text { middle of the task were } \\
\text { predictive of difference score. }\end{array}$ \\
\hline
\end{tabular}

Note. The exploratory analyses report only findings that differ from the primary analyses. 
Table 25

Summary of Intraclass Correlations Between Partners' Interactive Behavior $(N=80$ individuals).

Note. Task Irr. $=$ Task Irrelevance

$* * p<.01$. 
Figure 1.

Relation of Session Segment \& Tutoring Behaviors

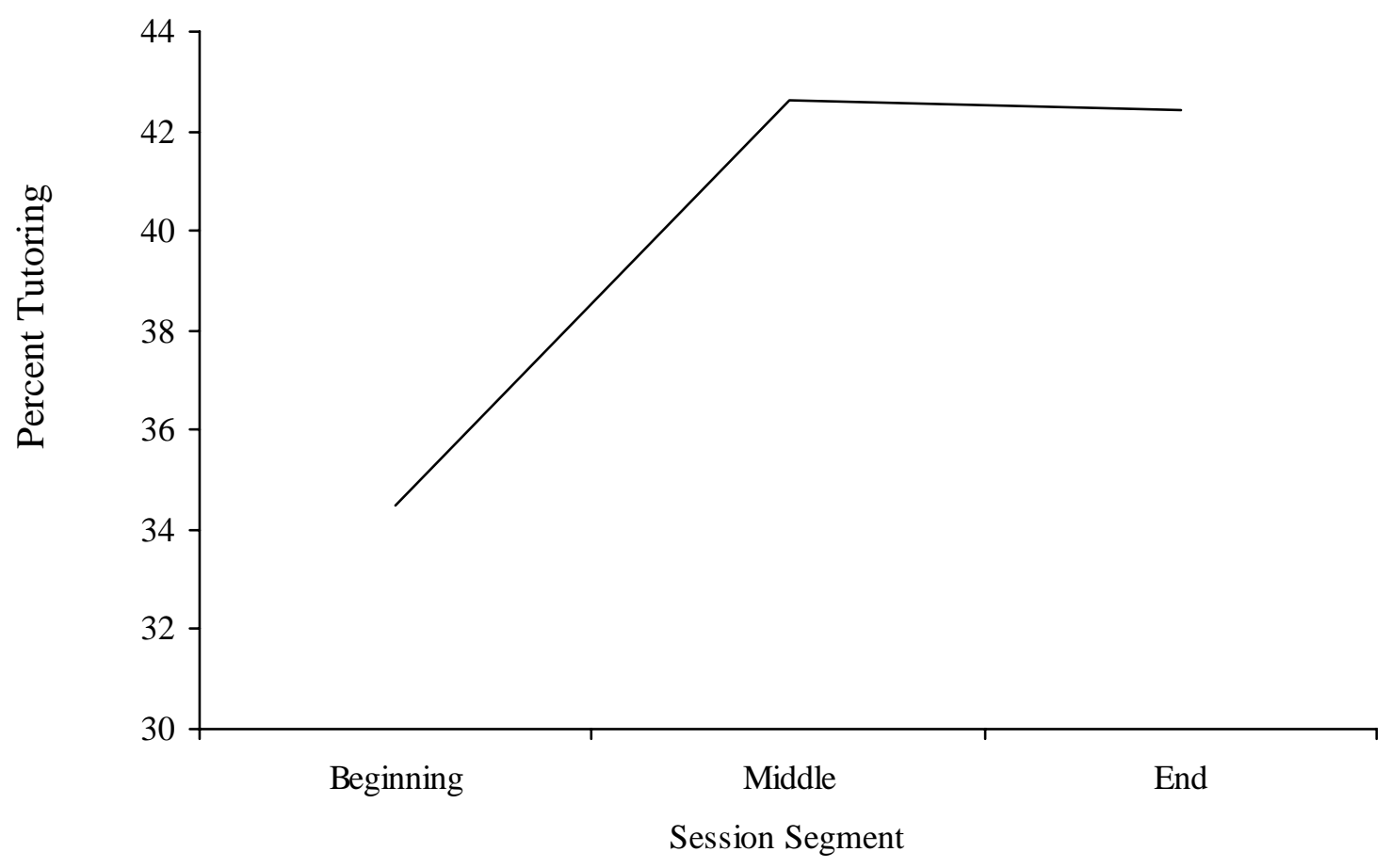


Figure 2.

Interaction Between Partner Familiarity and Session Segment for Task Irrelevance

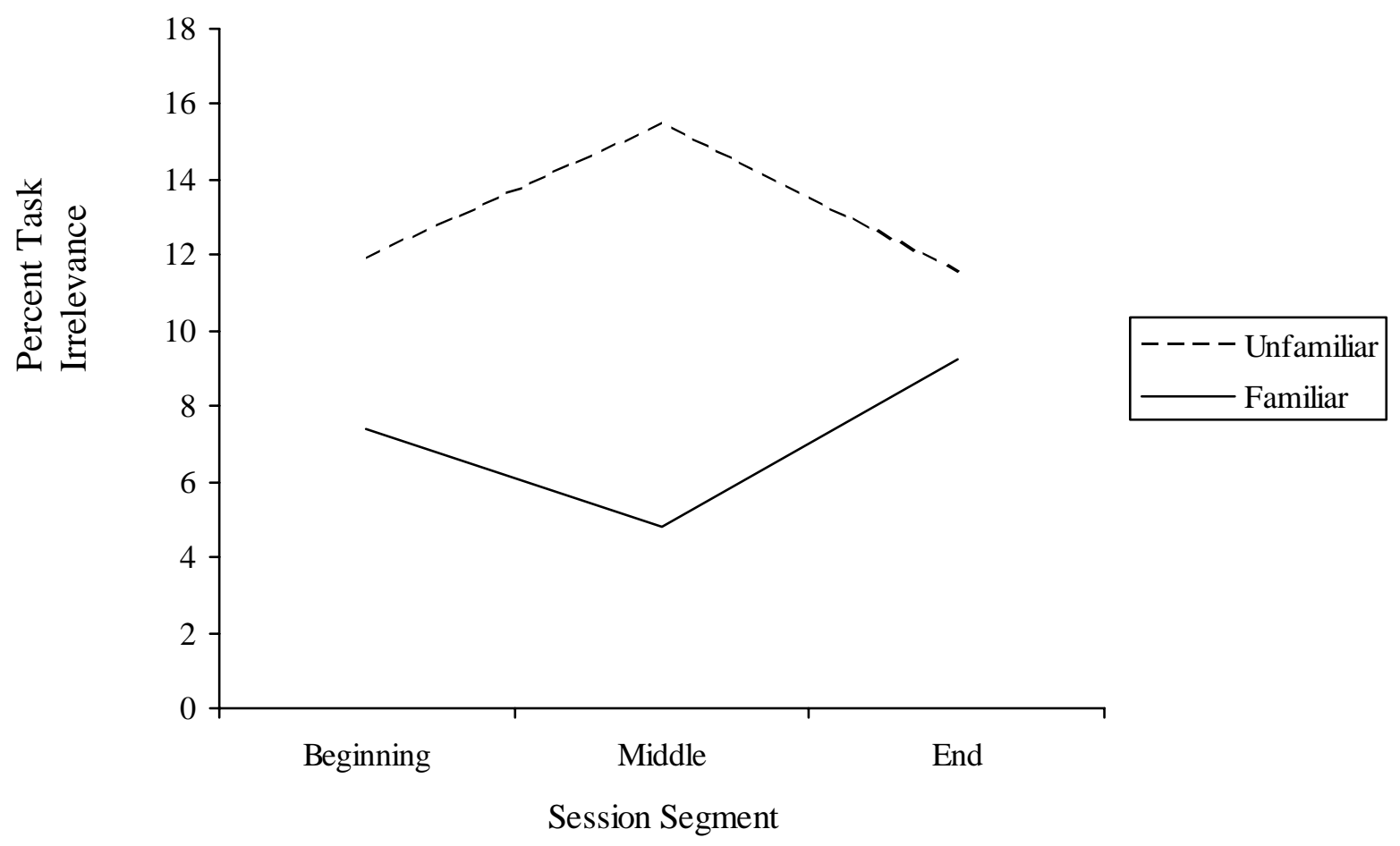




\section{Appendix A}

Everyday Problems Test Example Stimulus (Willis \& Marsiske, 1993)

\begin{tabular}{|l|c|c|c|}
\hline \multicolumn{1}{|c|}{ Services } & Benefit & Medicare Pays & You Pay \\
\hline HOSPITALIZATION & First 60 days & All but $\$ 760$ & $\$ 760$ \\
$\begin{array}{l}\text { Semiprivate room and } \\
\text { board, general nursing and } \\
\text { other hospital services and } \\
\text { supplies. } \\
\text { (Medicare payments based } \\
\text { on benefit periods; see pg. 3) }\end{array}$ & Beyond 150 days & All but $\$ 190$ a day $90^{\text {th }}$ day & N190 a day \\
\hline $\begin{array}{l}\text { SKILLED NURSING } \\
\text { FACILITY CARE }\end{array}$ & to $150^{\text {th }}$ day* & All but $\$ 380$ a day & \$380 a day \\
$\begin{array}{l}\text { Semiprivate room and } \\
\text { board, skilled nursing and } \\
\text { rehabilitative services and } \\
\text { other services and } \\
\begin{array}{l}\text { supplies.** } \\
\text { (Medicare coverage based on } \\
\text { benefit periods; see pg. 3) }\end{array}\end{array}$ & $\begin{array}{c}\text { Additional } 80 \\
\text { days }\end{array}$ & $\begin{array}{c}\text { All but } \$ 95 \text { a day } \\
\text { amount }\end{array}$ & $\begin{array}{c}\text { Up to } \$ 95 \\
\text { a day }\end{array}$ \\
\hline
\end{tabular}

What was the amount of the deductible an individual paid for Inpatient Hospital Services for the first 30 days?

Mr. Jones entered a nursing home on January 1 of 1997. How much did Part A Medicare pay for his care in July 1997? 
Appendix B

\section{WED Transcription Guidelines}

From Margrett, 1999

A. Audiotapes of the dyadic problem-solving interaction will be transcribed. Then the transcriptions will be reviewed while watching the videotapes to correct any errors and calculate the reliability. Our goal is to be a careful and accurate as possible throughout the transcription process. This will ensure that the tapes have been reliably transcribed. Reliabilities will be computed from the second pass with the videotape. Specifically, the number of words that are corrected will be calculated.

B. Open the file “/collcog/transcrp/transmas.doc/” in Word.

C. At the beginning, end of the transcription session, and periodically throughout, save the document in a NEW file. The new file should be saved as followed: “/collcog/transcrp/<id1id2>.doc/”.

D. Transcribe one problem-solving item at a time. Be sure that the transcription is typed under the correct problem-solving item (e.g., EPT, EPS, or ERR).

E. The transcription template is designed so that dialogue from both members of the dyad can be transcribed simultaneously. Type the dialogue under the appropriate column (i.e., male or female). Begin in the column of the person talking first. You should continue in that column until the other person speaks or there is a lengthy pause or shift in conversation.

F. Type all dialogue in capital letters. However, type environmental noise, nonverbal utterances (e.g., sneezes), and the examiner's comments in lowercase letters.

G. Insert punctuation where appropriate. Insert two spaces after each sentence.

H. Use the first initial of each name that is referred to within the dialogue (e.g., F for Frank).

I. Transcribe the entire interaction, verbatim. This includes example items and transitions from one item or problem domain to the next.

If the participant interjects comments or doesn't read a question verbatim, please transcribe the question verbatim. Otherwise, the abbreviation "(read ques)" can be substituted.

J. If participants go back to previous item, make a notation on the transcript and complete the transcription under the appropriate item header. 
If participants complete the final task, but continue talking after completion of the task you may make a notation and discontinue transcribing the post-task discussion. Finish transcribing when the participants close their materials after completing the last task.

“(conversation continues, seek video for other info)”

K. At the end of the transcription session, check spelling, scan the transcript and correct any errors.

L. At the beginning, end of the transcription session, and periodically throughout, save the document in a

NEW file. The new file should be saved as followed:

“/collcog/transcrp/<id1id2>.doc/".

M. After Transcription:

1. Mark top of audio tape with " $T$," and move to appropriate shelf.

2. Check off on Audio/Video list. Write any comments.

3. Print out one copy for video reliability check, and place in tray.

As a goal, transcription of 45 minute tapes should average about three to four hours. Some tapes may take more or less time. 
Appendix C

WED Transcript Coding

Coding Manual

About the Study:

This coding scheme was designed for a study where older married adults performed a task that is thought to be very closely related to the type of cognitive tasks that older adults experience on a daily basis. The task was performed both as an individual and as a member of a dyad. There were two types of dyads, half of the dyads consisted of a married dyad while the other half consisted of a male and a female dyad that has never met before. The dyads were video and audio taped during their performance of the task and the transcripts of these tapes will be used for coding purposes. The objective of the coding is to identify types of verbal behaviors that influence the outcome or performance level of the task.

\section{About the task:}

Here is a brief description of the task that was used in the study that we will be coding. As we discussed earlier, it is designed to closely resemble real life problems or situations that older adults may face on a daily basis. We will therefore be coding the interactions between dyads of older adults to determine what characteristics are associated with better or worse performances. The task being used is called the Everyday Problems Test (EPT).

Everyday Problems Test (EPT)

This task was designed to test older adult's ability to solve problems that are related to health, housekeeping, transportation, and telephone use. In this task, 
participants are asked to solve age-related problems such as setting up a medication schedule. There are 14 items on the test and the total number of correctly answered items measures performance.

\section{Macro versus Micro Coding}

This study will perform coding on two levels. The first type of coding that will be conducted is macro level coding. In this type of coding, the researcher must determine the presence of certain behaviors throughout the entire task. Each behavior will therefore only receive one score for each individual in the dyad for the course of the entire task. Micro level coding, on the other hand, examines each clause that is stated in the task. The transcripts will be divided into clauses or segments. Each segment will then be labeled according to the different behavioral codes. The total number of occurrences for each of the behaviors can then be calculated to determine how frequent the behavior occurred throughout the task.

\section{Macro Behavioral Coding:}

Macro behavioral coding is different from micro behavioral coding because it does not code each unit. Instead it gives a summary of a particular behavior throughout the entire task. Macro behavioral coding will be done using a four point likert scale where 1 = the behavior never occurred, 2 = the behavior rarely occurred, $3=$ the behavior sometimes occurred, and 4 = the behavior usually occurred. So after all micro coding has been completed and scored, macro coding will then rate the frequency of certain behaviors throughout the entire task for each member of the dyad. 


\section{Definitions for Categories of Behaviors for Macro Coding}

\section{Category: Task Irrelevance}

The task irrelevance category is designed to measure the degree to which the participant displayed verbal behavior that was not focused on the task at hand. If an individual discusses their personal life and the story appears to be relevant to completing the task it would not be considered task irrelevance. If the personal information is not relevant to the task at hand it would not be considered as task irrelevance. Note that the statement must be related to the task and must also contribute to a solution in order to not be considered task irrelevance. The frequency of these task irrelevance behaviors throughout the entire task should be taken into consideration when completing macro coding.

\section{Category: Demands}

Demands will measure behaviors related to controlling the other participant. This control can occur on different domains. For example, a participant may attempt to control the session, their partner, or the outcome of the task. A participant may attempt to control the session by telling their partner when it is time to move on to the next item. A person may attempt to control their partner by giving directives on how the person should behave. The outcome may be controlled by telling one's partner that their answer is incorrect.

\section{Category: Tutoring}

Tutoring refers to an individual participant's behaviors that are directed toward helping their partner. This category does NOT measure the usefulness or quality of the help. Instead, the intent of the behavior is being measured. For example, if the 
participant offers their partner help and the partner refuses to accept the help or the help turns out to not aid the partner's performance, the initiating behavior was still intended to give help and would therefore be considered as tutoring. Tutoring behaviors are TASK related. In other words, they are intended to help their partner improve performance on the task. Another common example of tutoring behavior is when an individual paraphrases or attempts to explain the question at hand to their partner. If the question is stated verbatim, however, it would be considered as “reads question” not tutoring.

\section{Category: Encouragement}

This category deals with verbal behaviors that encourage one’s partner to participate in the collaborative task. This type of encouragement is intended to positively affect how their partner feels about their self, their performance, or the situation. It is important to distinguish that encouragement is not necessarily intended to help complete the task, but is intended to give support concerning how their partner feels about the task or their performance. Encouragement usually comes in the form of positive statements that are said about one's partner or something that one’s partner said. Encouragement may also be prompts to get one’s partner to participate.

\section{Category: Collaborative}

This category deals with the extent that an individual in the dyad demonstrates a desire to work together with their partner. If the two individuals appear to listen to each other, take each other's opinions into account, and reach solutions to the problems together they would both be considered highly collaborative. On the other hand, if the two individuals do not appear to be working together or communicating well, they would be considered not very collaborative. Keep in mind, however, that the macro coding 
examines the level of occurrence for given behaviors for each individual in the dyad. It is therefore possible for one individual in the dyad to demonstrate a desire to work as a team and score high on collaborative behaviors and for their partner to demonstrate a lack of interest in communicating and working together, scoring low on collaborative behaviors. When coding the amount of collaboration that is present, it is therefore important to take into account how collaborative each individual in the dyad was throughout the entire task.

\section{Category: Competitive}

The competitive category will rate how often an individual engages in verbal behaviors that demonstrate that they are in competition with their partner. This often occurs by comparing the performance or skill level of their partner to their own performance or skill level. By making these statements the individual is stating that they perceive contributions being made by each individual in the dyad and that the contributions may or may not be equal.

\section{Category: Conflicting}

This category is used to determine the frequency of conflicting behaviors throughout the entire task. Conflicting behaviors are demonstrated by verbal behaviors that reflect disagreement between the two individuals in the dyad. Keep in mind that conflicting behavior is coded on the individual level the same as the other behavior categories. It is therefore possible for one individual in a dyad to have a high score in conflicting behavior and for their partner to have a low score on conflicting behavior. In this situation, one member of the dyad would be very disagreeable and confrontational 
while their partner would be appeasing and would attempt to reach agreements without confrontation.

\section{Micro Behavioral Coding}

The coding scheme was designed to code for verbal behaviors. The verbal interaction of the dyads performing each task was recorded and converted into a transcript. The transcripts will then be used to classify behaviors in seven major categories: 1) Demands 2) Tutoring 3) Task Irrelevance 4) Encouragement 5) Reads Question 6) Answers Question 7) Other Task Related Behaviors. These behaviors are coded on an individual level. Therefore the behavior does not have to be shared by both partners, if one partner demonstrates the behavior, it is coded for that partner alone. Therefore each individual will be coded separately from his or her partner. In addition to coding individuals separately, each clause will also be coded separately although surrounding clauses will be used to determine the context of the clause in question. The clauses are already marked and will be discussed in greater detail during practice coding. Definitions for Categories of Behaviors for Micro Coding

The coding scheme divides behaviors into seven major categories. The categories are thought to best represent variables that affect the interaction quality of older adults. Here is a definition of the major categories.

\section{Category: Demands (DEM)}

Demands measures behaviors related to controlling the other participant. This control can occur on different domains. For example, a participant may attempt to control the session, their partner, or the outcome of the task. A participant may attempt to control the session by telling their partner when it is time to move on to the next item. 
A person may attempt to control their partner by giving directives on how the person should behave. The outcome may be controlled by telling one's partner that their answer is incorrect or that a certain answer is the only possible solution.

\section{Examples of Demanding Behavior:}

/You write down the answers I give you./

/Let's move on to number three./

/No you're wrong. / This is the answer you need to put./

\section{Category: Tutoring (TUT)}

Tutoring refers to an individual participant's behaviors that are directed toward helping their partner. This category does NOT measure the usefulness or quality of the help. Instead, the intent of the behavior is being measured. For example, if the participant offers their partner help and the partner refuses to accept the help or the help turns out to not aid the partner's performance, the initiating behavior was still intended to give help and would therefore be considered as tutoring. Tutoring behaviors are TASK related. In other words, they are intended to help their partner complete or improve performance on the task. Tutoring behaviors therefore include practical help as well as more substantive assistance. In many instances tutoring behaviors may be similar to demanding behaviors but each clause can only be considered either tutoring or demands, not both. To better distinguish between demands and tutoring pay attention to how assertive the statement appears (whether the statement is a direct order or a suggestion) as well as the content and context of the statement (if the purpose of the statement is to help, it is tutoring, if the purpose is to control, it is demands). Below are examples of tutoring and demands. 
Demands: /Quit writing in that box. You need to write your answers over here./

Tutoring: /I don't think we are supposed to write in that box./

As this example demonstrates tutoring and demands can be very similar in some situations. By coding each individual clause, however, it is possible to determine which parts of a large statement are demands (controlling and giving orders to one’s partner) and which parts of the statement are tutoring (offering suggestions or providing information to one's partner). Another common example of tutoring behavior is when an individual paraphrases or attempts to explain the question at hand to their partner. If the question is stated verbatim, however, it would be considered as "reads question" not tutoring. In instances where the question is read out loud verbatim, the transcript states (reads question) and what is read is not typed on the transcript.

\section{Examples of Tutoring Behavior:}

/Maybe we should try working this out on paper./

/This one is a little tricky. You have to read about the items carefully./

/If they want the max. amount, we should use the biggest dosage./

\section{Category: Task Irrelevance (IRR)}

The task irrelevance category is designed to measure the degree to which the participant displayed verbal behavior that was not focused on the task at hand. If an individual discusses their personal life and the story appears to be relevant to completing the task it would not be considered task irrelevance. If the personal information is not relevant to the task at hand and to completing the task, it would be considered as task irrelevance. Note that the personal information must be related to the task and must also contribute to a solution to not be considered task irrelevance. In addition to personal 
information, small talk such as the time and temperature is considered task irrelevance. Also any statements that are made to the experimenter (E) are considered task irrelevance.

Examples of Task Irrelevance Behaviors:

/So, do you have any children?/

/I wonder what this study is about?/

/It's cold in here./

/Do you know what time it is?/

Category: Encouragement (ENC)

This category deals with verbal behaviors that encourage one's partner to participate in the collaborative task. This type of encouragement is intended to positively affect how their partner feels about their self, their performance, or the situation. It is important to distinguish that encouragement is not necessarily intended to help complete the task, but is intended to give support concerning how their partner feels about their involvement in the task or their performance. Encouragement usually comes in the form of positive statements that are said about one's partner or something that one's partner said. Encouragement may also be prompts to get one’s partner to participate. If encouragement occurs while a dyad is discussing something not related to the task, the particular clause that is encouraging is to be coded as encouragement, while surrounding clauses may be task irrelevance.

Examples of Encouragement:

/Good job./

/Yes, that's the same answer I was thinking/ 
/You are good at this./

\section{Category: Reads Question (RQS)}

This category is used when the participant reads the question verbatim. Sometimes the individual may read the question verbatim. In these instances the transcript says (reads question) instead of typing out the question verbatim. In these instances (reads question) is considered a separate clause and should be coded in the reads question category. Other times an individual may only read a portion of the entire section or may repeat a part of the question. The units involved in these verbal behaviors should also be considered reads question. The most important aspect of this category, however, is that the entire question or part of the question is read or stated word for word. If the question is summarized or paraphrased to help one's partner understand the meaning of the question it is considered a tutoring behavior. In order to code "reads question" accurately; it is therefore necessary to read the entire question before coding and to have the questions available as a reference during coding.

\section{Category: Answers Question (AQS)}

The category answers question will be used to code instances when an individual simply states a possible answer to a question. This includes instances when an individual answers a question, asks about a particular answer, or repeats an answer. This category does not, however, include instances when an answer is repeated along with a confirmation. In these instances one participant has given an answer and their partner has repeated the answer and also states that they agree (See encouragement for examples). These instances would be considered as encouragement because the confirmation would 
encourage one's partner to continue to participate and would also positively affect how their partner feels about their answer.

\section{Examples of Answers Question:}

/4 times a day/

/The max dose is 4/

/4/

/more water/

\section{Category: Other Task Related Behaviors (OTH)}

This category will be used for any type of verbal behavior that is related to the task (not task irrelevance) but cannot be placed in any of the other categories (demands, encouragement, tutoring, reads question, or answers question). This type of verbal behavior will include any verbal behavior that cannot be placed in another category but does appear to be related to the task. The category also includes units that are difficult to understand but does appear to be related to the task. It is very important, however, to be sure that the clause does not qualify as task irrelevance, demands, encouragement, tutoring, reads question, or answers question before labeling it as other (OTH).

\section{Procedure:}

The coding will occur on both the macro and micro level. Micro level coding will determine the actual frequency of the different behaviors. This is done by labeling what behavior category each clause falls into. As you will soon see, many of the clauses are very small (some may consist of only one or two words). By examining such a small clause in isolation it would be difficult to determine what type of behavior the clause would represent. It is therefore necessary to examine each clause, taking into 
consideration the context it is being used in and the content of surrounding clauses. The macro level coding rates the overall level of occurrence of the behaviors and should be completed and scored before micro coding begins. More information about micro and macro level coding follows.

Official coding will not begin until several practice-coding sessions have been performed to assure that everyone has experience with and a full understanding of the coding scheme. When the practice is complete you will be given a schedule that assigns certain transcripts to certain individuals. The assignments are done on a weekly basis so use the schedule to determine what transcripts to code for each week. The transcripts are labeled using a male ID and a female ID. Both the male and female ID for a given transcript is stated on the schedule. Some transcripts will be coded by more than one individual to assure that scores given by one rater are similar to scores given by other raters.

Once you determine what transcripts you are to code you must obtain a scoring sheet before coding begins. There will be a section on the top of both pages of the scoring sheet for you to write your name along with the male and female ID number for the transcript being coded. It is very important that the correct ID number is placed in the proper location and to fill out all information on both page one and page two in case the scoring sheets become separated. Once this is done, it is time to code the transcript.

There will be seven questions asking overall how you would rate the presence of Tutoring, Encouragement, Task Irrelevance, Demands, Collaborative, Competitive, and Conflicting behaviors for each individual throughout the course of the entire Everyday Problems Test (macro codes). This will be done using a four point likert scale where $1=$ 
the behavior never occurred, 2 = the behavior rarely occurred, 3 = the behavior sometimes occurred, and $4=$ the behavior usually occurred. Four of these codes will also have micro level codes (tutoring, encouragement, task irrelevance, and demands). You must therefore complete ALL macro level codes before starting the more detailed micro level coding. Once these scores have been obtained for each of the seven behaviors for both individuals, micro level coding can begin.

Once all macro coding is complete, it is time to start the micro coding. To do this, above each clause write an abbreviated form of the coding category that you feel best describes the clause. The abbreviations are as follows: Tutoring $=$ TUT, Demands $=$ DEM, Encouragement $=$ ENC, Task Irrelevance $=$ IRR, Reads Question $=$ RQS, Answers Question $=$ AQS, and Other $=\mathrm{OTH}$. The Everyday Problems test is divided into 14 items. At the end of each item it is necessary to count the total number of times each of the seven behaviors occurred. After these totals have been calculated, record the totals with the corresponding behavior for the given item. Use a pencil when writing on the score sheet so that any mistakes on the score sheet can be erased and corrected. Do not mark out any mistakes or draw arrows to clarify where a score belongs on the score sheet. If a mistake is so large that it cannot be erased, fill out another score sheet and throwaway the old one. Once these frequency scores have been calculated for each behavior category on each of the 14 items, coding is complete for the transcript. Check to make sure that all information is filled out correctly on the score sheet and place the transcript back in the file cabinet and the score sheet in the designated file. 


\section{Appendix D \\ WED Unitization Rules}

While unitizing transcripts separate the printed dialog into phrases that express complete thoughts by using slashes. Below are some guidelines to help you decide what to do in some tricky situations.

1. Repeats: When a phrase is repeated several times, count each time it is said as a separate phrase.

Examples:

/NO YOU HAVE TO/ YOU HAVE TO REPORT THOSE/

/THE FIRST/ THE FIRST ONE 216-555-1111 IS 3 TIMES/

2. After punctuations: Any time there is punctuation noting a new sentence, separate the two sentences even if a sentence is only followed by a single word or number.

Example:

/WHICH 2 DEDUCTIONS?/OK/

3. Conjunctions: If the sentence is running on with a lot of conjunctions (and, but, or, however, so) and expresses more than one complete thought, place the slash showing separate thoughts before the conjunction.

Examples:

/I'M DOING MORE THAN A DOT/I'M PUTTING A CROSS ON THAT/ AND I'M MARKING IT C-R./

/SO YOU GOT 6/ THAT'S 180 AND 2/ SO THAT'S 380?/ ONE NOW?/ 


\section{/THIS IS CORRECT/HOWEVER, THAT MAY ALSO BE CORRECT/}

4. Nonverbals: If nonverbal actions are documented in the middle of a sentence, consider it separate from the sentence that contains it.

Example:

HMM WE'RE ON / (reads question) / \# 5.

5. Turns: A unit cannot carry over different turns. Even if a turn is a one word statement or utterance, it is still considered an independent unit.

Example:

MALE

FEMALE

\begin{tabular}{|l|l|}
\hline /HMM/ & /MEDICARE FORMS/ \\
\hline /NUMBER THREE/ & \\
\hline
\end{tabular}




\section{Appendix E}

\section{Rules for Calculating Unitization Reliability}

1. To calculate unitization reliability it is necessary to examine the two copies of the transcripts simultaneously.

2. Have a separate piece of paper with a column for agree and a column for disagree.

3. Compare the two transcripts clause by clause using the transcript that was completed first as the correct or master transcript.

4. If the two transcripts agree on a given clause then make a tally mark of that in the agree column.

5. If the two transcripts disagree on a given clause, make a tally mark of the disagreement in the disagree column. Calculating disagreed totals can be more complicated than calculating agreed totals. Below is some clarification in calculating the number of disagreed clauses.

** Most of the time when a clause is disagreed on, one rater has something marked as one clause while the other has it marked as two clauses. Remember that the original transcript is used as the master so the transcript completed by the second researcher is being compared to the master transcript.

Example:

Unitizer 1 “master transcript”: /Yeah/ that's right/

Unitizer 2: /Yeah that's right/

This example would be marked as two disagreements because the master transcript had the phrases marked as two separate clauses. The additional unitizer therefore disagreed on two clauses. If this example were reversed, however, it would be scored as one 
disagreement because the master transcript would have the phrase marked as one clause so the additional unitizer would have disagreed with the one clause.

**Other times the unitizers disagree more than once on a given statement. In these cases, still compare the additional transcript to the master transcript.

Example:

Unitizer 1 “master transcript”: /Do you know if this will take a long time or will we be able to leave soon?/

Unitizer 2: /Do you know / if this will take a long time / or will we be able to leave soon?/

This example would be marked as one disagreement because the original transcript has the phrase marked as one clause so the additional transcript disagreed with the one clause. If this example was reversed and unitizer one had the statement marked as three clauses and unitizer two had the transcript marked as one clause, it would be scored as three disagreements because the additional transcript disagreed with the three clauses on the master transcript.

6. After the two transcripts have been compared, add the number of agreed clauses with the number of disagreed clauses to get the total number of clauses. This total number of clauses is equal to the total number clauses found in the master transcript. Then divide the total number of agreements by the total number of clauses (agree + disagree) to get the percent agreement for the transcript. 